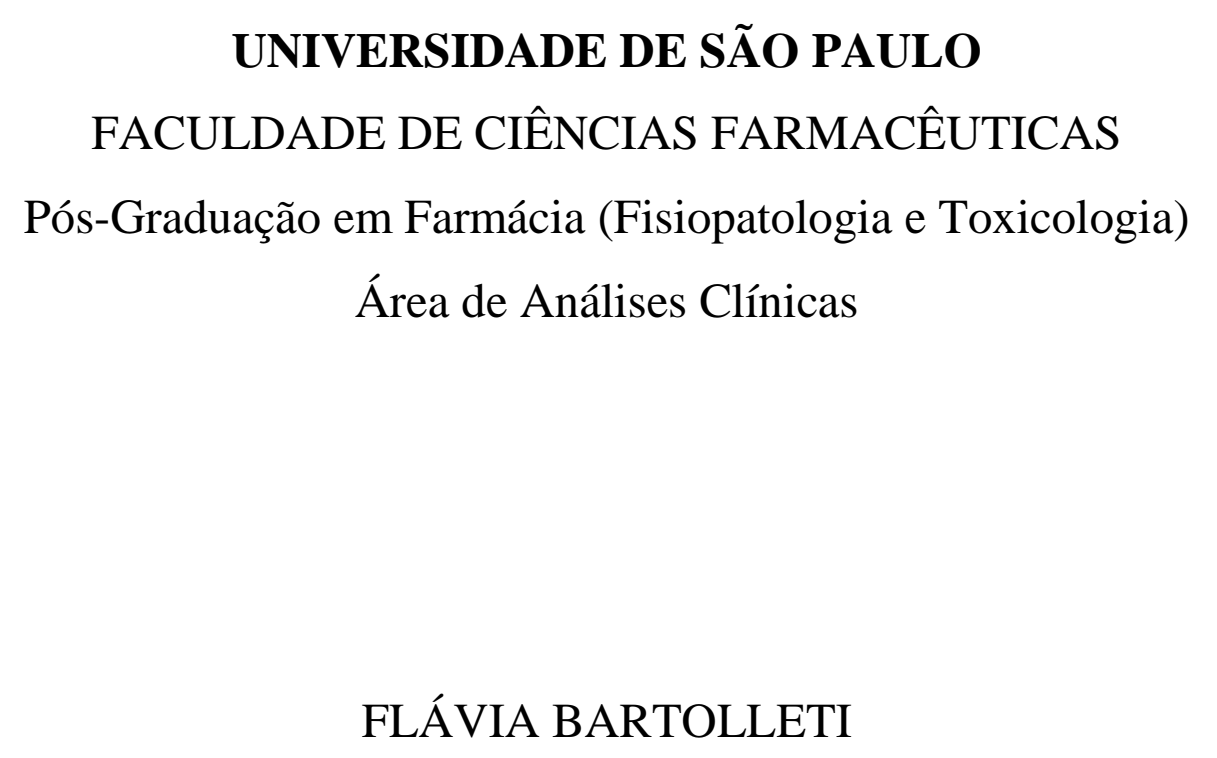

FLÁVIA BARTOLLETI

Avaliação da relação genética e perfil de sensibilidade de Klebsiella pneumoniae resistentes à polimixina $\mathrm{B}$

São Paulo

2016 


\title{
FLÁVIA BARTOLLETI
}

\author{
Versão original
}

\section{Avaliação da relação genética e perfil de sensibilidade de Klebsiella pneumoniae resistentes à polimixina $\mathrm{B}$}

Dissertação apresentada à Faculdade de Ciências Farmacêuticas da Universidade de São Paulo para obtenção do grau de Mestre em Ciências.

Programa de Pós-Graduação em Farmácia: Área de Análises Clínicas

Orientador: Prof. Dr. Jorge Luiz Mello Sampaio

São Paulo 
Autorizo a reprodução e divulgação total ou parcial deste trabalho por qualquer meio convencional ou eletrônico, para fins de estudo e pesquisa, desde que citada a fonte.

\section{Ficha Catalográfica}

Elaborada pela Divisão de Biblioteca e

Documentação do Conjunto das Químicas da USP.

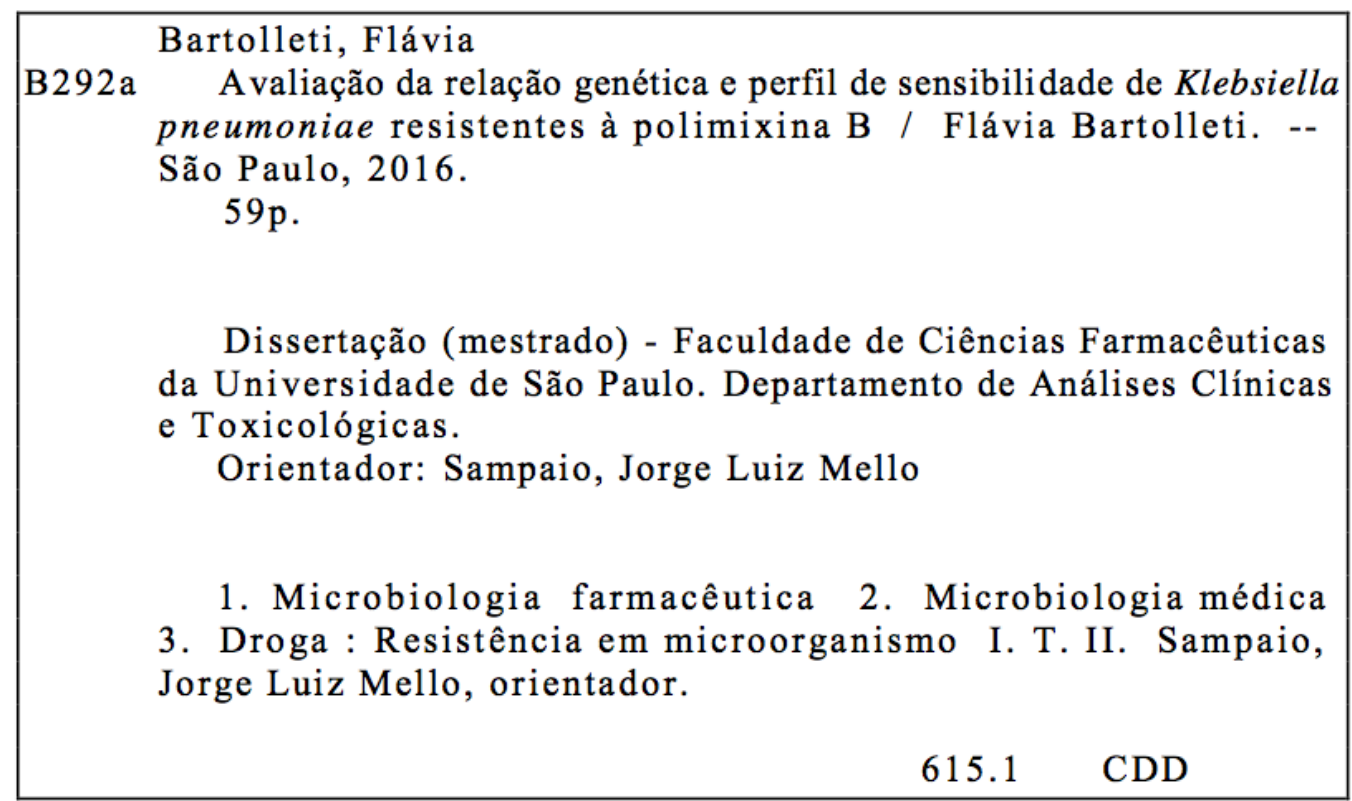


BARTOLLETI, F. Avaliação da relação genética e perfil de sensibilidade de Klebsiella pneumoniae resistentes à polimixina $\mathrm{B}$.

Dissertação apresentada à Faculdade de Ciências Farmacêuticas da Universidade de São Paulo para obtenção do grau de Mestre em Ciências.

Aprovado em de de 2016

Comissão Julgadora

Prof. Dr. Jorge Luiz Mello Sampaio

Orientador / Presidente

$1^{\circ}$ examinador

$2^{\circ}$ examinador 
À Universidade, como forma de retribuí-la pela diversidade de conhecimentos e culturas que fizeram desses últimos 10 anos os melhores da minha vida. 


\section{AGRADECIMENTOS}

Ao meu orientador, Professor Jorge, pelos ensinamentos, confiança e paciência, mas principalmente por me mostrar que é com audácia que atingimos os maiores objetivos.

Aos meus pais e ao meu irmão, por me apoiarem nesta trajetória desde a matrícula na graduação até a presente defesa de mestrado. Obrigada por compreenderem meu estilo de vida caótico e me perdoem por todas as centenas de ligações perdidas no celular. Amo vocês.

Aos colegas microbiologistas, com os quais tive o prazer de trabalhar em conjunto, dividir experiências acadêmicas e construir a amizade ao longo do mestrado. Cito, em especial: Bruna, colega para todas as horas; Juliana, quem puxou minha orelha toda vez que fiz bagunça, e não foi pouca; Darlan, e seus dedinhos de prosa; Fabi, nossa querida técnica.

Às queridas colegas do HU-USP, Silvinha e Lílian, pelo auxílio na realização dos experimentos de PFGE, os quais foram indispensáveis para a realização deste trabalho.

Aos meus amigos, pela descontração nos dias difíceis e pela descontração maior ainda nos dias felizes. Às minhas colegas das equipes de basquete e rugby, agradeço a raça e apoio dentro e fora das quadras e campos, e peço desculpas desde já por não poder jogar mais uma INTERUSP.

À Faculdade de Ciências Farmacêuticas, a Farmacinha, que há 120 anos contribui no ensino e pesquisa das ciências farmacêuticas neste país. Tenho a honra de fazer parte desta história e dizer que meu sangue é bordô.

Ao Instituto Fleury, por disponibilizar dados, isolados bacterianos, material e infraestrutura, sem os quais este estudo não seria possível.

Ao Conselho Nacional de Desenvolvimento Científico e Tecnológico (CNPq) pela concessão da bolsa e apoio financeiro. 
“' 'It was much pleasanter at home,' thought poor Alice, 'when one wasn't always growing larger and smaller, and being ordered about by mice and rabbits. I almost wish I hadn't gone down that rabbit-hole - and yet - and yet - it's rather curious, you know, this sort of life! I do wonder what can have happened to me! When I used to read fairy-tales, I fancied that kind of thing never happened, and now here I am in the middle of one!'”

(Lewis Carroll, Alice's Adventures in

Wonderland - 1865) 


\title{
RESUMO
}

\author{
BARTOLLETI, F. Avaliação da relação genética e perfil de sensibilidade de Klebsiella \\ pneumoniae resistentes à polimixina B. 59 f. Dissertação (Mestrado) - Faculdade de \\ Ciências Farmacêuticas, Universidade de São Paulo, São Paulo, 2016.
}

INTRODUÇÃO: O aumento da incidência de infecções causadas por bactérias resistentes a múltiplos antimicrobianos limita cada vez mais as opções terapêuticas, dificultando o tratamento e aumentando os índices de morbidade e mortalidade, além dos gastos em saúde. Ao longo dos últimos cinco anos, essa limitação tem levado ao reestabelecimento do uso de antimicrobianos consideradas ultrapassados, como as polimixinas. Este grupo passou a ser utilizado com cada vez mais frequência no tratamento de infecções causadas por microrganismos gram-negativos resistentes aos carbapenêmicos. As enterobactérias, em particular a espécie Klebsiella pneumoniae, tem apresentado frequentemente esse perfil, porém, a resistência à polimixinas têm sido relatada, eliminando essa importante alternativa terapêutica. Apesar da importância do tema, são escassas as publicações sobre frequência de resistência às polimixinas em $K$. pneumoniae e a relação clonal entre isolados resistentes à polimixina B no Brasil. OBJETIVOS: Avaliar a relação genética, perfil de sensibilidade antimicrobiana e mecanismos de resistência às polimixinas em $K$. pneumoniae. MATERIAIS E MÉTODOS: A execução deste trabalho dividiu-se em duas partes principais: (i) levantamento de dados de culturas positivas para $K$. pneumoniae da rotina de pacientes hospitalizados em instituições atendidas pelo serviço de análises clínicas do Fleury Medicina e Saúde; (ii) confirmação das concentrações inibitórias mínimas (CIM) para polimixina B, avaliação da relação clonal por eletroforese em campos pulsados (PFGE),e sequenciamento de múltiplos loci (MLST), avaliação da integridade do gene $m g r B$ e da presença do gene $m c r$ 1 por PCR entre isolados resistentes à polimixina $\mathrm{B}$ e aos carbapenêmicos (CPRKp). RESULTADOS e CONCLUSÕES: Na análise de 3.085 isolados de K. pneumoniae obtidos de pacientes internados em 11 hospitais da Grande São Paulo entre os anos de 2011 e 2015, foi evidenciado um aumento estatisticamente significativo na resistência aos carbapenêmicos de 6,8\% em 2011 para 35,5\% em 2015. Em 2015, KPC foi detectada em 96,2\% dos isolados resistentes aos carbapenêmicos. A distribuição das concentrações inibitórias mínimas de polimixina $\mathrm{B}$ entre todos os isolados de $K$. pneumoniae evidenciou uma distribuição bimodal com a CIM de $2 \mathrm{mg} / \mathrm{L}$ como o valor de ponto de corte para a susceptibilidade à polimixina $\mathrm{B}$; assim, 3,6\% do número total de isolados sensíveis aos carbapenêmicos foram interpretados como resistentes enquanto essa proporção foi de $22,5 \%$ entre as resistentes aos carbapenêmicos (CRKp). Entre esses últimos isolados também houve um aumento estatisticamente significativo na tendência anual de resistência à polimixina $\mathrm{B}$, de $0 \% \mathrm{em}$ 2011 para 27,1\% em 2015. Estas taxas variaram de 0,7\% em 2011 para 3,9\% até junho de 2014 entre os sensíveis aos carbapenêmicos. Entre os antimicrobianos alternativos, a amicacina e a tigeciclina foram os compostos mais ativos. A análise por PFGE de 60 isolados de CPRKp obtidos de pacientes distintos nos anos de 2014 e 2015 evidenciou dois grandes grupos clonais: CPRKp1 e CPRKp2, os quais segundo a análise por MLST pertencem, respectivamente, aos grupos ST11 e ST437, ambos do complexo clonal 258. Foi observado o mesmo grupo ST entre isolados obtidos dentro de um mesmo hospital e também entre diferentes hospitais, públicos e privados. O mecanismo de resistência mais comum entre os isolados de CPRKp foi a presença de sequências de inserção interrompendo o gene $m g r B$. O gene $m c r-1$ não foi detectado em nenhum dos isolados.

Palavras-chave: multirresistência bacteriana; polimixina B; colistina; Klebsiella pneumoniae; $\mathrm{KPC}, m g r B, m c r-1$. 


\section{ABSTRACT}

BARTOLLETI, F. Genetic relationship assessment and antimicrobial sensitivity profile of polymyxin B resistant Klebsiella pneumoniae. 59 p. Dissertation (Master of Science) Faculdade de Ciências Farmacêuticas, Universidade de São Paulo, São Paulo, 2016.

INTRODUCTION: The increasing incidence of infections caused by bacteria resistant to multiple antimicrobials increasingly limits therapeutic options, making treatment difficult and increasing the morbidity and mortality and health spending. Over the past five years, this limitation has led to the reestablishment of the use of antimicrobials deemed outdated, such as polymyxins. This group is now used with increasing frequency to treat infections caused by carbapenem-resistant gram-negative microorganisms. Enterobacteria, especially Klebsiella pneumoniae, have often presented this profile, however, resistance to polymyxins have been also reported, eliminating this important therapeutic alternative. Despite the importance of this issue, the publications are scarce on the polymyxins resistance frequency in $K$. pneumoniae and clonal relationship among isolates resistant to polymyxin B in Brazil. OBJECTIVES: To evaluate the genetic relationship, antimicrobial susceptibility profile and polymyxin B resistance mechanisms in K. pneumoniae. MATERIALS AND METHODS: The execution of this work was divided into two main parts: (i) survey data on routine cultures positive for $K$. pneumoniae from patients hospitalized in institutions attended by the clinical analysis service of Fleury Health and Medicine; (ii) confirmation of to polymyxin B minimum inhibitory concentrations (MIC), evaluation of clonal relationship by electrophoresis pulsed field gel electrophoresis (PFGE), multilocus sequence typing (MLST), evaluation of the integrity of the $m g r B$ gene and the presence of $m c r-1$ gene by PCR among isolates resistant to polymyxin $\mathrm{B}$ and carbapenems (CPRKp). RESULTS AND CONCLUSIONS: The analysis of 3,085 K. pneumoniae isolates obtained from inpatients from 11 hospitals in the São Paulo urban area between 2011 and 2015, has shown a statistically significant increase in carbapenem resistance from $6.8 \%$ in 2011 to $35.5 \%$ in 2015. In 2015, KPC was detected in $96.2 \%$ of isolates resistant to carbapenems. The polymyxin B MIC distribution of all Klebsiella pneumoniae showed a bimodal distribution with the MIC of $2 \mathrm{mg} / \mathrm{L}$ as the cutoff value for polymyxin B susceptibility; thus, $3.6 \%$ of the total number of isolates susceptible to carbapenems were interpreted as resistant while this proportion was $22.5 \%$ among carbapenem-resistant isolates (CRKp). Among these isolates there was also a statistically significant increase in the annual trend of polymyxin B resistance, from $0 \%$ in 2011 to $27.1 \%$ in 2015 . These rates ranged from $0.7 \%$ in 2011 to $3.9 \%$ by June 2014 between carbapenem-susceptible isolates. Among alternative antimicrobials, amikacin and tigecycline were the most active compounds. The analysis by PFGE of 60 CPRKp isolates obtained from different patients in the years 2014 and 2015 showed two major clonal groups: CPRKp1 and CPRKp2, which according to the analysis by MLST belong respectively to ST11 and ST437 groups, both from clonal complex 258. We observed the same ST group of isolates obtained within a hospital and between different public and private hospitals. The most common mechanism of polymyxin B resistance among CPRKp isolates was the presence of insertion sequences interrupting the $\operatorname{mgrB}$ gene. The $m c r-1$ gene was not detected in any of the isolates.

Keywords: multidrug resistance; polymyxin B; colistin; Klebsiella pneumoniae; KPC; mgrB; mor-1. 


\section{LISTA DE FIGURAS}

Figura 1 Modelo representativo das principais interações químicas entre a molécula de polimixina e a membrana externa de uma bactéria Gram negativa.

Figura 2 Modelo da ativação do sistema de dois componentes PmrA/PmrB frente a vários sinais em Salmonella typhimurium.

Figura 3 Representação esquemática do locus do gene mgrB de Klebsiella pneumoniae.

Figura 4 Evolução da resistência aos carbapenêmicos por Klebsiella pneumoniae isolados de pacientes internados em hospitais privados da Grande São Paulo, 2011-2015.

Figura 5 Distribuição das concentrações inibitórias mínimas de polimixina B entre isolados de Klebsiella pneumoniae estratificadas por susceptibilidade aos carbapenêmicos.

Figura 6 Evolução da resistência à polimixina $\mathrm{B}$ entre o total de isolados de Klebsiella pneumoniae e segundo a sensibilidade aos carbapenêmicos.

Figura 7 Mapa representativo da distribuição dos 10 hospitais em que foram obtidos os 60 isolados de Klebsiella pneumoniae deste estudo.

Figura 8 Foto de gel obtido por eletroforese de campo pulsado (PFGE) para exemplificação.

Figura 9 Diversidade clonal e integridade do gene $m g r B$ entre isolados de Klebsiella pneumoniae resistentes a carbapenêmicos e polimixina B obtidos de pacientes hospitalizados na Grande São Paulo (2014 e 2015).

Figura 10 Foto de gel obtido através da eletroforese de fragmentos de DNA após a PCR para amplificação do gene $m g r B$ para exemplificação. 


\section{LISTA DE TABELAS}

Tabela 1 Tabela 1. Lista de iniciadores utilizados e condições das reações de PCR

Tabela 2 Tabela 2. Lista de iniciadores utilizados e condições da reação de sequenciamento com Big Dye Terminator ${ }^{\circledR}$

Tabela 3 Tabela 3. Características demográficas dos isolados de Klebsiella pneumoniae incluídos na análise estatística da base de dados do Fleury Medicina e Saúde (2011 a 2015)

Tabela 4 Tabela 4. Susceptibilidade a antimicrobianos alternativos em Klebsiella pneumoniae estratificado por resistência aos carbapenêmicos e polimixina B (2011 a 2015) 


\section{LISTA DE ABREVIATURAS}

AUC Área sob a curva concentração-tempo

CAMHB Do inglês, cation-adjusted Mueller-Hinton broth

CIM Concentração inibitória mínima

CMS Colistimetato de sódio

CPRKp Klebsiella pneumoniae resistentes aos carbapenêmicos e à polimixina $\mathrm{B}$

CRKp Klebsiella pneumoniae resistentes aos carbapenêmicos

CSKp Klebsiella pneumoniae sensíveis aos carbapenêmicos

KPC Do inglês, Klebsiella pneumoniae carbapenemase

KPC-Kp Klebsiella pneumoniae produtoras de KPC

IMP Imipenem

L-Ara4N 4-amino-4-deoxi-L-arabinose

LB Luria Broth

LPS Lipopolissacarídeo

MER Meropenem

mcr-1 Do inglês, mobile colistin resistance-1

MLST Do inglês, multilocus sequence typing

pEtN Fosfoetanolamina

$\mathrm{pb} \quad$ Pares de bases

PFGE Do inglês, pulsed-field gel electrophoresis

PCR Do inglês, polymerase chain reaction

PK/PD Perfil farmacocinético e farmacodinâmico

SDS Do inglês, sodium-dodecyl sulfate

UPGMA Do inglês, unweighted pair group method with arithmetic mean

UTI Unidade de terapia intensiva 


\section{LISTA DE SIGLAS}

ANVISA Agência Nacional de Vigilância Sanitária

ATCC American Type Culture Collection

CLSI Clinical and Laboratory Standards Institute

EUCAST European Committee on Antimicrobial Susceptibility Testing 


\section{LISTA DE SÍMBOLOS}

$\begin{array}{ll}{ }^{\circ} \mathrm{C} & \text { Graus Celsius } \\ \mathrm{kg} / \mathrm{m}^{2} & \text { Kilogramas por metro ao quadrado } \\ { }^{\circledR} & \text { Marca registrada } \\ \mu \mathrm{L} & \text { Microlitros } \\ \mathrm{mg} / \mathrm{L} & \text { Miligramas por litro } \\ \mathrm{mg} / \mathrm{ml} & \text { Miligramas por mililitros } \\ , & \text { Minutos } \\ \chi 2 & \text { Qui-quadrado } \\ " & \text { Segundos }\end{array}$


1. INTRODUÇÃO

1.1. A multirresistência bacteriana aos antimicrobianos....................................... 16

1.2. Polimixinas.......................................................................................... 17

1.2.1. Histórico................................................................................. 17

1.2.2. Estrutura e mecanismo de ação......................................................... 18

1.2.3. Aspectos farmacológicos................................................................ 19

1.2.4. Aspectos toxicológicos................................................................ 20

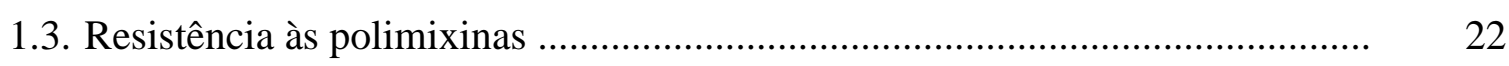

1.3.1. Mecanismo de resistência à polimixinas.............................................. 22

1.3.2. Resistencia às polimixinas por Klebsiella pneumoniae......................... 24

1.3.3. Terapia combinada....................................................................... 27

1.3.4. Atual panorama da resistência a polimixinas...................................... 28

1.3.5. Estudos brasileiros acerca da resistência às polimixinas....................... 29

1.4. Considerações finais................................................................................. $\quad 30$

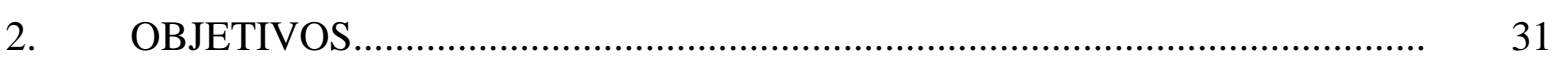

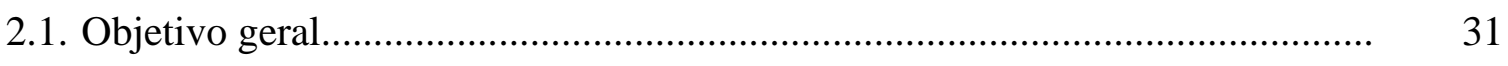

2.2. Objetivos específicos............................................................................ 31

3. MATERIAL E MÉTODOS......................................................................... 32

3.1. Análise estatística do banco de dados do Fleury Medicina e Saúde................. 32

3.1.1. Critérios de inclusão e exclusão........................................................... 32

3.1.2. Metodologia aplicada pelo Fleury Medicina e Saúde na determinação e interpretação da sensibilidade aos antimicrobianos.......................................... 33

3.1.3. Determinação do perfil de resistência aos carbapenêmicos e presença de Klebsiella pneumoniae carbapenemase (KPC) ................................................ 33

3.1.4. Análise estatística................................................................................... 33

3.2. Avaliação da relação clonal e mecanismo de resistência entre isolados de K.pneumoniae resistentes à polimixina B obtidos de pacientes hospitalizados.......... 34

3.2.1. Seleção, isolamento e armazenamento de bactérias................................. 34

3.2.2. Teste de sensibilidade à polimixina B.................................................. 34

3.2.3. Tipagem molecular por eletroforese em campo pulsado (PFGE)............ 35 
3.2.4. Tipagem por sequenciamento de múltiplos loci (MLST)........................ 36

3.2.5. Amplificação e análise do gene bla KPC.................................................. 36

3.2.6. Amplificação e análise do gene $\operatorname{mgrB}$................................................... 37

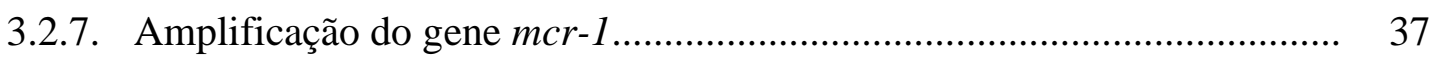

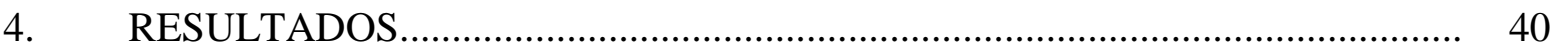

4.1. Análise estatística do banco de dados do Fleury Medicina e Saúde..................... 40

4.2. Análise da relação clonal entre isolados de Klebsiella pneumoniae ...................... 43

4.3. Análise do mecanismo de resistência à polimixina B ........................................ 47

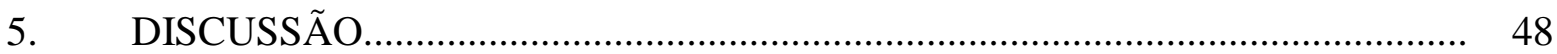

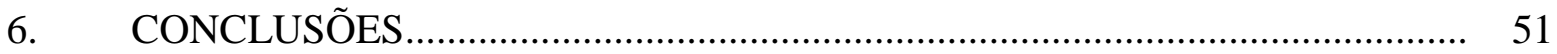

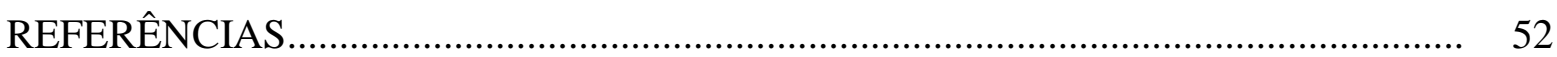




\section{INTRODUÇÃO}

\subsection{A multirresistência bacteriana aos antimicrobianos}

Em 1928, Alexander Fleming descreveu a propriedade antimicrobiana da penicilina, a primeira molécula da extensa família dos antibióticos betalactâmicos, descoberta por acaso quando o cientista percebeu que colônias de Staphylococcus aureus não cresciam ao redor de um fungo do gênero Penicillium, que contaminara uma de suas placas de Petri (Nobelprize.org, s.d.). Apesar das doenças infecciosas serem consideradas um dos mais letais males humanos na época, Fleming não recebeu a devida credibilidade pela sua descoberta, e apenas na década de 40 iniciou-se a utilização clínica da penicilina, tendo grande sucesso no tratamento de infecções estreptocócicas e estafilocócicas (Tavares, W., 2014). Esse fato deu início à chamada "Era dos Antibióticos", alterando profundamente o manejo de infecções bacterianas, e, desde então, houve um grande trabalho desenvolvido pela comunidade científica e pela indústria farmacêutica em busca de novas descobertas para que hoje esteja disponível um vasto arsenal de moléculas com ação antimicrobiana.

O sucesso obtido na cura dessas enfermidades, no entanto, nunca foi pleno, graças à capacidade das bactérias de contornar o meio hostil gerado por um ou mais antimicrobianos (CHOPRA; HESSE; O’NEILL, 2002). A multirresistência aos antimicrobianos tornou-se um dos grandes problemas de saúde pública e tem aumentado consideravelmente nos últimos anos, preocupando as autoridades sanitárias e desafiando mais uma vez o homem a lidar com esses pequenos gigantes. Nas últimas décadas do século $\mathrm{XX}$, entretanto, as indústrias farmacêuticas reduziram drasticamente seus investimentos para a descoberta de novos antimicrobianos e focaram seus esforços em fármacos para tratamento de doenças crônicas. Por sua vez as instituições governamentais não se preocuparam em desonerar os investimentos em novos antimicrobianos (BOUCHER et al., 2009). A problemática atual reside na limitação das opções de fármacos disponíveis para o tratamento de infecções graves, o que em muitos casos acaba por delongar o tempo de internação hospitalar e aumentar os índices de morbidade e mortalidade (COSGROVE, 2006). Por isso, torna-se necessário o conhecimento acerca do patógeno e do perfil de resistência esperado para cada infecção, a fim de orientar o tratamento empírico, bem como das alternativas terapêuticas no caso do surgimento da multirresistência bacteriana (LEVY HARA et al., 2013). 


\subsection{Polimixinas}

\subsubsection{Histórico}

Polimixinas são antimicrobianos conhecidos desde a década de 40. Das cinco polimixinas originalmente descritas (A a E), duas delas são utilizadas na prática clínica: a polimixina $\mathrm{B}$ e a polimixina $\mathrm{E}$, também denominada colistina. A polimixina $\mathrm{B}$ foi originalmente isolada do Bacillus polymyxa em 1947 (ORTWINE et al., 2015), enquanto a colistina em 1949 do Bacillus polymyxa var. colistinus, e é a mais utilizada no mundo (DIJKMANS et al., 2014). Utilizou-se amplamente as polimixinas até meados dos anos 70, quando altos índices de eventos adversos relacionados ao uso das polimixinas foram elucidados, principalmente renais e neurológicos (KOCH-WESER et al., 1970), fato que somou-se à disponibilidade de outros antimicrobianos que traziam sucesso terapêutico com menor índice de toxicidade, tais como as cefalosporinas de terceira geração e posteriormente os carbapenêmicos (LANDMAN et al., 2008). Entretanto, em função do recente aumento da multirresistência bacteriana e da emergência de organismos extensivamente resistentes, os carbapenêmicos tiveram uma grande limitação na sua eficácia e assim houve a reintrodução das polimixinas na prática clínica (GIAMARELLOU; POULAKOU, 2009; VAN DUIN et al., 2013; VELKOV et al., 2013).

Se por um lado as polimixnas foram bem sucedidas graças à sua eficácia na resolução das infecções causadas por esses microorganismos resistentes, por outro lado a retomada de sua utilização trouxe de volta à tona a problemática em relação aos eventos adversos, a qual foi deixada em esquecimento por décadas. Vale lembrar que na época de aprovação das polimixinas para o mercado (anos 50) a legislação acerca dessa toxicidade e exigências na produção não eram tão rígidas como atualmente, culminando em informações limitadas a respeito das características farmacológicas das polimixinas, o que pode explicar a ocorrência dos muitos problemas relacionados ao uso desses antimicrobianos (ORTWINE et al., 2015). Felizmente, com o retorno do uso das polimixinas, obrigou-se também que o conhecimento acerca dessas moléculas fosse atualizado, existindo hoje um contingente significativo de estudos a respeito de farmacocinética, farmacodinâmica e toxicidade das polimixinas, através dos quais é possível construir estratégias a fim de minimizar a ocorrência de eventos adversos. 


\subsubsection{Estrutura e mecanismo de ação}

As polimixinas são antimicrobianos polipeptídicos cíclicos, cujo modelo do mecanismo de ação mais aceito baseia-se na sua interação direta com o lipídeo A, componente do lipopolissacarídeo (LPS) presente na membrana externa de organismos gramnegativos. Em pH fisiológico, as polimixinas possuem resíduos amina protonados, apresentando natureza catiônica que permite a afinidade eletrostática com os grupos fosfato (aniônicos) presentes no LPS. Assim, essa interação desloca íons cálcio e magnésio que outrora estabilizavam a carga do LPS, permitindo a inserção da cauda lipofílica presente na molécula das polimixinas (figura 1), ocasionando assim o desarranjo e a desestabilização da membrana externa. Esse desarranjo leva ao aumento da permeabilidade na célula bacteriana, a qual permite maior absorção do antimicrobiano (absorção autopromovida), bem como liberação do conteúdo das células e, em seguida, a morte celular bacteriana devido ao desequilíbrio osmótico (ARNOLD; FORREST; MESSMER, 2007; VELKOV et al., 2013).

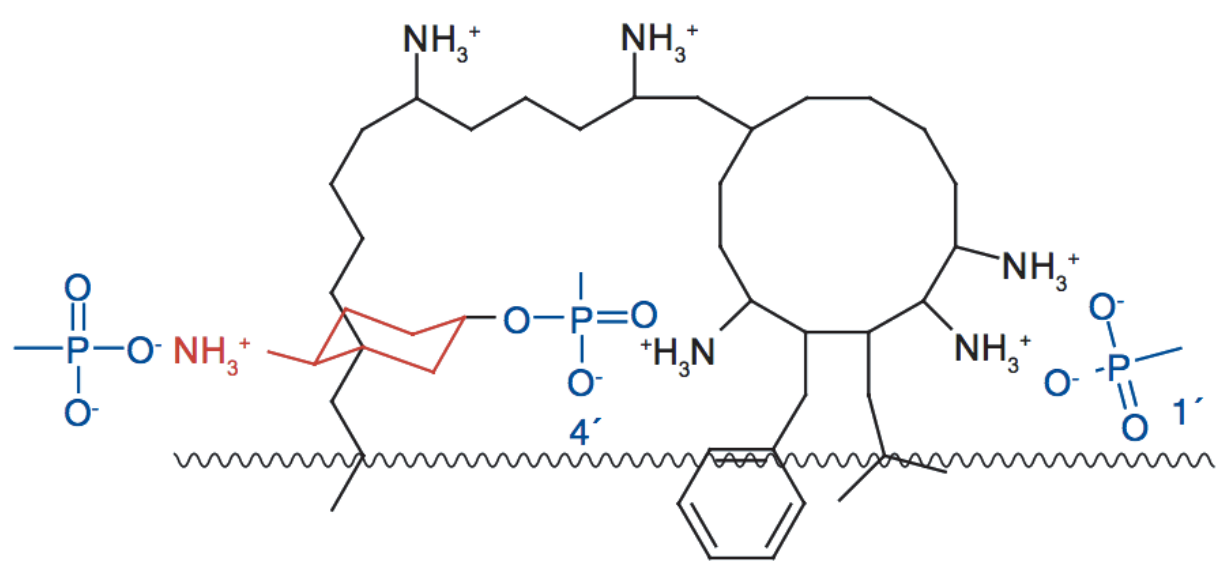

Figura 1. Modelo representativo das principais interações químicas entre a molécula de polimixina e a membrana externa de uma bactéria Gram negativa. Os resíduos catiônicos do ácido diaminobutírico (aminas protonadas) interagem eletrostaticamente com os grupos aniônicos dos grupos fosfato do lipídio A, componente do lipopolissacarídeo. As interações hidrofóbicas ocorrem entre os resíduos dos aminoácidos presentes no ciclo (leucina e fenilalanina) e a cauda lipídica com os lipídeos da membrana, representada pela linha ondulada. (VELKOV et al., 2013)

Por desestruturar a membrana lipídica, as polimixinas atuam de maneira semelhante a um detergente. Assim, quanto maior o conteúdo de fosfolipídios na membrana externa de bactérias que permita as interações eletrostáticas e hidrofóbicas com as moléculas das polimixinas, maior a sensibilidade a esses antimicrobianos. Por essa razão, sua ação é mais eficaz em bactérias gram-negativas, tais como os gêneros Acinetobacter, Klebsiella, 
Enterobacter, Escherichia, Stenotrophomonas, Salmonella, Shigella e Pseudomonas. Alguns gêneros, entretanto, possuem resistência intrínseca a esses antimicrobianos por apresentam características de membrana diferenciadas: Providencia, Neisseria, Proteus, Serratia e Burkholderia (VELKOV et al., 2013).

\subsubsection{Aspectos farmacológicos}

O perfil farmacocinético e farmacodinâmico (PK/PD) que melhor descreve a ação das polimixinas é a razão entre a área sob a curva concentração-tempo e a concentração inibitória mínima (AUC/CIM), na qual a exposição ao antimicrobiano por algum tempo é suficiente para sua atividade microbicida, porém, por ser uma relação CIM-dependente, a concentração do antimicrobiano deve ser maior se a bactéria apresenta maior nível de resistência (ZAVASCKI, 2014). A polimixina B encontra-se disponível sob forma de sal sulfatado em formulações parenterais e tópicas no Brasil, ao passo que a colistina é utilizada na forma de pró-fármaco sulfometilado inativo: o colistimetato de sódio (CMS), cuja administração é intravenosa (ARNOLD; FORREST; MESSMER, 2007). Em razão disso, apesar de possuírem características semelhantes quanto ao espectro de ação, sua farmacocinética é bastante distinta.

Por ser administrada em sua forma ativa, a polimixina B atinge rapidamente seu pico de concentração plasmática, enquanto a curva de concentração plasmática da colistina é mais tardia, podendo demorar até 8 horas para atingir a concentração máxima após a administração do CMS (KARAISKOS et al., 2015; ORTWINE et al., 2015). Este fato é potencialmente de grande relevância clínica no manejo de infecções sistêmicas graves. Além do mais, por ser convertido à colistina nos túbulos renais, existe grande variação individual na metabolização do CMS, principalmente entre indivíduos com déficit da função renal. Pacientes com depuração renal reduzida têm menor eliminação de CMS, necessitando de ajuste de dose, enquanto que a polimixina B é excretada por outras vias do metabolismo, não necessitando de modificação mesmo com níveis variados de depuração de creatinina (NATION et al., 2015). É preciso reafirmar, no entanto, que o monitoramento da função renal é recomendado para minimizar o risco de nefrotoxicidade independentemente da polimixina utilizada (BISWAS et al., 2012; JUSTO; BOSSO, 2015). A taxa de conversão do CMS para o antimicrobiano ativo também é baixa, sendo estimada em 30\% (COUET et al., 2011), porém esse parâmetro é impreciso, uma vez que o CMS pode ser convertido nos fluidos biológicos ex vivo utilizados nos ensaios de quantificação. Não obstante, no processo de sulfometilação da colistina, 
existem cinco aminas passíveis de sofrer adição; logo a extensão da adição do grupo sulfometilado (de uma a cinco adições) modifica a velocidade de conversão à colistina, uma vez que existe variabilidade também entre diferentes produtores de formulações de CMS, bem como produtos variados da conversão in vivo do CMS em colistina (KARAISKOS et al., 2015; KASSAMALI; DANZIGER, 2015).

A vantagem farmacocinética do uso do CMS, entretanto, está no fato de que a maior parte do pró-fármaco é eliminado pela urina e, assim, boa parte da colistina recém-formada acaba concentrando-se também nesse compartimento, o que é mais vantajoso no manejo de infecções do trato urinário, uma vez que polimixina B é minimamente eliminada pela urina (NATION et al., 2015).

\subsubsection{Aspectos toxicológicos}

A toxicidade, particularmente renal e neurológica, é um empecilho do uso das polimixinas desde o início da sua utilização clínica e culminou, como já citado anteriormente, no abandono dessas moléculas assim que novos quimioterápicos, mais seguros, foram descobertos. A nefrotoxicidade relacionada ao uso de polimixinas se manifesta no decréscimo da depuração de creatinina, hematúria, proteinúria, cilindrúria, oligúria e até necrose tubular aguda (FALAGAS; KASIAKOU; SARAVOLATZ, 2005). As lesões provocadas estão relacionadas ao decréscimo na atividade de filtração glomerular e disfunção mitocondrial, a qual gera dano oxidativo por incremento na produção de espécies reativas de oxigênio, resultando em citotoxicidade, alteração do endotélio tubular, da perfusão e hemodinâmica renal, até morte celular por apoptose (VATTIMO et al., 2016).

Há, no entanto, uma grande variabilidade entre os diversos estudos de efeitos adversos ao uso de polimixinas, a qual prejudica uma determinação universal acerca da real incidência da nefrotoxicidade. Isso ocorre devido a uma série de fatores, entre eles a falta de um consenso sobre a própria definição de toxicidade utilizada por cada estudo dentre as várias manifestações citadas acima, além das variações das subpopulações dos pacientes quanto ao estado clínico e depuração renal de creatinina (JUSTO; BOSSO, 2015; PHE et al., 2014). Dessa forma, os níveis de toxicidade secundária ao uso de polimixinas variaram entre $20 \%$ e $60 \%$ entre os diversos estudos (KASSAMALI; DANZIGER, 2015).

O uso do CMS nos anos 60 foi erroneamente associado a um menor índice de efeitos adversos, uma vez que com a adição do grupo sulfometilado diminuía-se a dor associada à aplicação intramuscular, porém se sabe hoje que a polimixina B possui toxicidade equivalente 
ou até mesmo menor. Uma hipótese para esta mudança de paradigma foi a subestimação do potencial tóxico do CMS devido à sua ineficiente taxa de conversão em colistina, a qual leva à necessidade de se utilizar doses mais elevadas de CMS para que se atinja o estado de equilíbrio estável (steady state) de colistina necessário para a atividade microbicida, estipulado em 2,0 mg/L (EUCAST, 2015). Constatou-se que o incremento de dose de CMS pode gerar maior nefrotoxicidade em relação àquela observada com o uso de polimixina $\mathrm{B}$, fato que contrasta fortemente com a ideia um pró-fármaco ideal (JUSTO; BOSSO, 2015; NATION et al., 2015). De fato, estudos retrospectivos realizados com pacientes tratados com polimixinas corroboraram doses mais elevadas com maior incidência de nefrotoxicidade, considerando o critério de RIFLE (do inglês: risk, injury, failure, loss and end stage) para lesão renal baseado na elevação da creatinina sérica (DUBROVSKAYA et al., 2015; RIGATTO et al., 2016).

Com relação à posologia, a administração intravenosa de polimixina B em dose única diária apresentou toxicidade menor e de início mais insidioso quando relacionada à administração a cada 6 horas em modelos murinos, tendo também menor deposição no tecido renal, o que pode ser explicado por um mecanismo de saturação da captação da polimixina B pelas células dos túbulos proximais (ABDELRAOUF et al., 2012). Entende-se, assim, que o pico de dose não eleva a acumulação do antimicrobiano nos rins e não prejudica a sua eficácia graças ao seu perfil PK/PD relacionado à AUC/CIM, enquanto que doses fracionadas e a liberação contínua do CMS permitem maior exposição e, consequentemente, nefrotoxicidade (RIGATTO et al., 2016).

Entretanto, ainda não há um consenso bem estabelecido e evidências suficientes acerca de qual polimixina é a mais segura em termos de nefrotoxicidade. Além do mais, estudos apontam outras variáveis, além da dose, que influenciam na ocorrência de dano renal, tais como idade avançada (AKAJAGBOR et al., 2013), uso concomitante de vancomicina (DUBROVSKAYA et al., 2015; KUBIN et al., 2012; TUON et al., 2014), e índice de massa corpórea maior que $25 \mathrm{~kg} / \mathrm{m}^{2}$ (KUBIN et al., 2012).

Os efeitos neurotóxicos relacionados ao uso de polimixinas ocorrem devido à sua afinidade lipídica pela bainha de mielina de neurônios, manifestando-se com sintomas de tontura, fraqueza muscular, parestesia, surdez parcial, distúrbios visuais, vertigem, confusão, alucinações, convulsões, ataxia e bloqueio neuromuscular. O último desses geralmente produz uma síndrome semelhante à miastenia, bem como insuficiência respiratória ou apneia devido à paralisia dos músculos respiratórios (FALAGAS; KASIAKOU; SARAVOLATZ, 2005), e pode estar relacionado à inibição competitiva da acetilcolina pela polimixina na fenda 
sináptica e ao aumento do período de despolarização por depleção de cálcio (JUSTO;

BOSSO, 2015). É contraindicado, por essa razão, o uso concomitante de polimixinas com bloqueadores neuromusculares, tais como a toxina botulínica (UpToDate).

Constatou-se, entretanto, que na atual utilização de polimixinas não são observados níveis de nefrotoxicidade e neurotoxicidade tão frequentes tais como relatados nos estudos mais antigos. O estudo de Falagas et al. (FALAGAS; KASIAKOU; SARAVOLATZ, 2005) descreveu uma série de variáveis que podem ter levado à essa discrepância: formulações de polimixinas que apresentavam excipientes muito tóxicos, dosagem superior à utilizada hoje, falta de ajuste de dose em pacientes com insuficiência renal, uso errôneo de formulações intramusculares diretamente na corrente sanguínea, outras enfermidades e medicamentos que também se associavam à diminuição da função renal e alterações neurológicas.

Apesar de todas as disposições citadas, ainda são necessários mais estudos descrevendo a farmacocinética e potencial tóxico das polimixinas, particularmente da polimixina $B$, uma vez que foram realizados mais estudos a respeito do uso de CMS. Sendo assim, ainda não é possível avaliar com segurança e forte evidência científica qual é a polimixina menos tóxica e mais eficaz para uso clínico (KASSAMALI; DANZIGER, 2015). As evidências mais atuais corroboram na exigência da necessidade de monitoramento terapêutico, a fim de minimizar os eventos adversos graças ao tênue limiar entre a concentração farmacológica eficaz na atividade microbicida e a concentração tóxica. Em pacientes com função renal inalterada, a concentração sérica ideal de polimixinas corresponde ao ponto de corte para sensibilidade antimicrobiana de 2,0 mg/L estabelecido pelo EUCAST (do inglês European Committee on Antimicrobial Susceptibility Testing) (EUCAST, 2015), enquanto que concentrações acima de $2,5 \mathrm{mg} / \mathrm{L}$ já estão associadas à ocorrência de nefrotoxicidade. Por essa razão, tem sido recomendada a terapia combinada no caso de patógenos com CIM superior à 1,0 mg/L (NATION et al., 2015).

\subsection{Resistência às polimixinas}

\subsubsection{Mecanismo de resistência à polimixinas}

As bactérias gram-negativas podem apresentar mecanismos de resistência que são comuns para colistina e polimixina $\mathrm{B}$, a maioria deles ocorre devido às modificações da estrutura da membrana externa bacteriana, principalmente do LPS. Outros mecanismos encontrados são sistemas de bombas de efluxo, espessamento da cápsula polissacarídica e 
modificações nas concentrações de proteínas específicas da membrana externa (FALAGAS; RAFAILIDIS; MATTHAIOU, 2010; ZAVASCKI et al., 2007). Não obstante, a resistência a esses antimicrobianos pode se manifestar durante a terapia graças aos fenômenos de heterorresistência e resistência adaptativa (BARIN et al., 2013; MELETIS et al., 2011) e podem estar relacionados a doses sub-ótimas do antimicrobiano durante a terapia (LI et al., 2006).

Modificações químicas do lipídeo A presente no LPS conferem resistência à polimixinas através da adição covalente de moléculas catiônicas no grupo fosfato e na porção oligossacarídica, tais como a 4-amino-4-deoxi-L-arabinose (L-Ara4N) e a fosfoetanolamina (pEtN). Com isso, o padrão iônico da membrana externa é alterado, diminuindo a carga aniônica total, no qual é inviabilizada a interação eletrônica com a molécula das polimixinas, reduzindo assim sua afinidade (HELANDER et al., 1996). Os sistemas enzimáticos de dois componentes PmrA/PmrB e PhoQ/PhoP já foram descritos como mediadores da adição da LAra4N na membrana externa de Gram-negativos em resposta à determinados estímulos externos: presença de peptídios antimicrobianos, depleção de cátions divalentes, $\mathrm{pH}$ baixo e presença de ferro trivalente (MOSKOWITZ et al., 2012). Não apenas a ação das polimixinas é afetada, mas também de outros peptídios antimicrobianos endógenos produzidos por leucócitos polimorfonucleares em resposta à invasão do patógeno (LLOBET et al., 2011). Encontra-se na figura 2 uma representação esquemática desse sistema de sinalização (CHEN; GROISMAN, 2013).

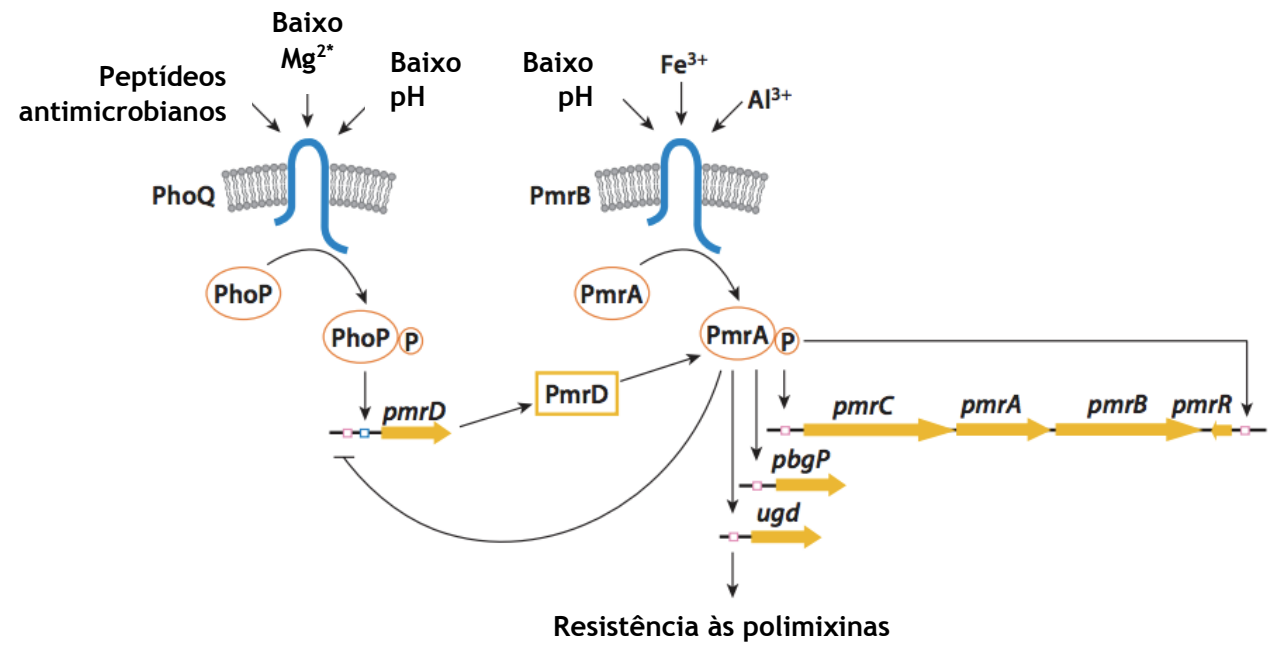

Figura 2. Modelo da ativação do sistema de dois componentes PmrA/PmrB frente a vários sinais em Salmonella typhimurium. A transcrição dos genes ativados pela fosforilação da proteína PmrA mediam as modificações de membrana externa de organismos Gram negativos, tal como a adição de grupos catiônicos no lipídeo A do lipopolissacarídeo, promovendo a resistência às polimixinas. (CHEN; GROISMAN, 2013) 
Recentemente, Yu-Yun e colegas descreveram pela primeira vez a resistência à polimixinas mediada por gene de localização plasmidial. O gene designado mcr-1 (mobile colistin resistance) codifica uma fosfoetanolamina transferase capaz de transferir pEtN para o LPS. O grupo também avaliou a alta capacidade de transferência plasmidial entre isolados de Escherichia coli com sucesso na transmissão horizontal da resistência à colistina e com estabilidade mesmo sem a pressão seletiva das polimixinas (LIU et al., 2015). Observou-se a presença do $m c r-1$ em isolados de E. coli recolhidos de $15 \%$ de 523 amostras de carne para consumo humano, em 21\% de 804 animais de corte (frango e suínos) durante 2011 a 2014, e 16 entre 1.322 amostras de pacientes com infecção, sendo três isolados de Klebsiella pneumoniae. A alta incidência da presença do $m c r-1$ na pecuária e avicultura não surpreende, uma vez que as polimixinas são também utilizadas na medicina veterinária, não apenas no tratamento, mas também na profilaxia de infecções provocadas por enterobactérias, sendo até disponibilizadas na água e alimento desses animais. Não ocorre, entretanto, um controle adequado desse uso e ainda mais preocupante é o fato que, diferentemente do uso em humanos, as polimixinas tem sido initerruptamente utilizadas em animais na Europa há pelo menos 50 anos, e pouco se sabe a respeito da transmissão horizontal da resistência às polimixinas entre animais e humanos (CATRY et al., 2015). A presença do gene $m c r-1$ vem sendo detectada em uma série de países em todo o mundo: Europa, Américas, Norte da África e Ásia, em amostras do meio ambiente, animais, alimentos e em amostras obtidas de humanos (IRRGANG et al., 2016). No Brasil, a presença do gene $m c r-1$ foi relatada em 16 amostras de E. coli isoladas de frango e suínos no Sudeste do país (FERNANDES et al., 2016) e também em 17 amostras E. coli obtidas de frango em três granjas distintas, curiosamente os animais nunca haviam sido expostos à polimixina B (LENTZ et al., 2016). No início deste ano, um único isolado de E. coli com a presença do gene $m c r-1$ foi obtido a partir de uma cultura de lesão em pé diabético (FERNANDES et al., 2016).

\subsubsection{Resistencia às polimixinas por Klebsiella pneumoniae}

Entre os microorganismos cuja resistência antimicrobiana tem sido motivo de grande preocupação da comunidade médica está a $K$. pneumoniae, uma enterobactéria de grande importância em infecções do trato urinário e trato respiratório, bem como bacteremias e infecções abdominais. Além disso, é crescente também a relevância desse patógeno em infecções hospitalares, particularmente em unidades de terapia intensiva (UTI), e em infecções oportunistas (JIAO et al., 2015). Recentemente a Sociedade Americana de Doenças 
Infecciosas classificou os oito principais microorganismos da atualidade cuja resistência aos antimicrobianos é de maior preocupação, incluindo na lista a $K$. pneumoniae; são eles os “ESKAPE”: Enterococcus faecium, Staphylococcus aureus, K. pneumoniae, Acinetobacter baumanii, Pseudomonas aeruginosa e espécies de Enterobacter (BOUCHER et al., 2009).

$\mathrm{O}$ destaque para a $K$. pneumoniae entre as bactérias de maior preocupação reside principalmente na facilidade de transferência horizontal de sequências codificadoras de betalactamases em elementos genéticos móveis (ANDRADE et al., 2011; QUEENAN; BUSH, 2007), as quais são o mecanismo de resistência mais comumente encontrado entre bacilos gram-negativos (KANJ; KANAFANI, 2011). Atualmente são as carbapenemases, betalactamases capazes de hidrolisar carbapenêmicos e quase todos os outros membros da classe dos betalactâmicos, as enzimas de maior importância na multirresistência bacteriana por organismos gram-negativos (LEVY HARA et al., 2013). A K. pneumoniae é a espécie que mais comumente produz enzimas do tipo KPC (do inglês: Klebsiella pneumoniae carbapenemase), classe de carbapenemase mais disseminada no planeta e que têm sido detectada com frequência cada vez maior em diversas regiões do mundo, incluindo o Brasil (DE ROSA et al., 2015; NORDMANN; CUZON; NAAS, 2009). O aumento progressivo da taxa de resistência aos carbapenêmicos em Enterobactérias é motivo de grande preocupação, pois são os antimicrobianos de primeira escolha para o tratamento de infecções graves causadas esse grupo de microrganismos (VAN DUIN et al., 2013). Não obstante, as infecções por K. pneumoniae resistentes aos carbapenêmicos (CRKp) estão associadas à maior mortalidade quando comparadas às infecções provocadas por $K$. pneumoniae sensíveis aos carbapenêmicos (CSKp) (JIAO et al., 2015).

Dentre as CRKp, o complexo clonal 258 (CC258) é o mais frequentemente detectado, e é considerado de alto risco devido à sua associação com evolução clínica desfavorável e altas taxas de resistência antimicrobiana (DHAR et al., 2016; GOMEZ-SIMMONDS et al., 2015; LOMBARDI et al., 2015). O CC258 inclui os grupo clonal ST258 (ST, do inglês sequence type) e seus variante de único locus ST11 e ST437. As polimixinas estão entre os poucos agentes antimicrobianos que mantêm atividade contra CRKp e tem representado um componente-chave no tratamento dessas infecções. No entanto, o surgimento de resistência às polimixinas tem sido relatado repetidamente, tornando este quadro ainda mais preocupante. Ademais, surtos de infecções por $K$. pneumoniae do grupo ST258 resistentes à polimixinas também tem sido relatados (BOGDANOVICH et al., 2011; GARZA-RAMOS et al., 2014; MARCHAIM et al., 2011; MAVROIDI et al., 2016). O estudo de Arena e colaboradores (ARENA et al., 2016) aponta que a maior virulência e capacidade de disseminação desse 
grupo clonal independe do perfil de sensibilidade à colistina, de forma que as maiores taxas de mortalidade relacionadas às infecções por isolados resistentes às polimixinas estão relacionadas à redução das opções terapêuticas disponíveis.

O estudo de Cannatelli e colaboradores (CANNATELLI et al., 2013) identificou diferenças moleculares entre dois isolados de K. pneumoniae produtoras de KPC (KPC-Kp) obtidos de um mesmo paciente com o intervalo de 30 dias durante a internação. No período, o paciente recebeu uma série de antimicrobianos, como tigeciclina e, gentamicina, meropenem e colistina. O primeiro isolado era sensível à colistina, enquanto o segundo, obtido após 25 dias de tratamento com o antibiótico, resistente. A única diferença molecular entre os isolados foi a inativação do gene $m g r B$, o qual codifica uma pequena proteína de membrana. Em outras espécies bacterianas, esse gene regula negativamente o mecanismo de transdução de sinal do sistema $\mathrm{PhoQ} / \mathrm{PhoP}$, o qual está associado à modificação do Lipídeo A presente no LPS, tal como explicado no item 1.3 .1 e representado na figura 2. A reintrodução do gene $m g r B$ no isolado resistente à polimixina levou à redução da CIM para os mesmos níveis do primeiro isolado. $\mathrm{O}$ inverso ocorreu quando o mesmo gene fora inativado no primeiro isolado, conferindo-lhe resistência à colistina. No estudo de Poirel e colaboradores (POIREL et al., 2015), foram estudados 47 isolados de K. pneumoniae resistentes à colistina, nos quais 12 apresentavam a sequência do gene $\operatorname{mgrB}$ truncadas por sequências de inserção, sendo caracterizado como um dos fatores que conferem resistência à colistina (figura 3). O mesmo grupo descreveu que mutações, ainda que pontuais, nos diferentes genes que codificam proteínas dessa cascata de sinalização, também estão envolvidas na resistência às polimixinas em K. pneumoniae mesmo que mantida a integridade do gene mgrB (JAYOL et al., 2014).

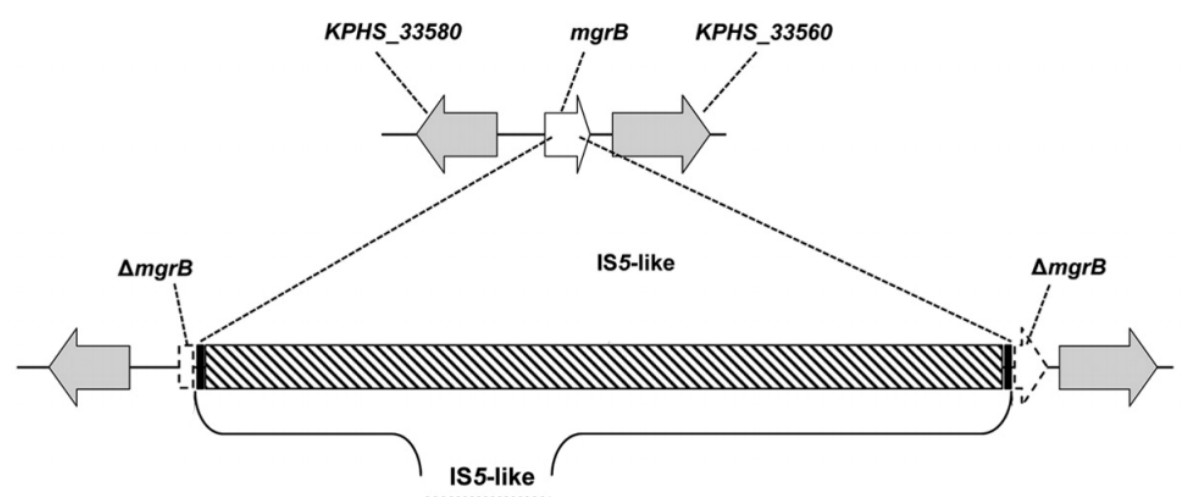

Figura 3. Representação esquemática do locus do gene mgrB de Klebsiella pneumoniae. Acima está representado o gene íntegro (seta branca), ao passo que abaixo há a presença de uma sequência de inserção (IS5-like) truncando o gene, o qual passa a ser representado pelo retângulo e seta com linhas descontínuas. 
O estudo de Campos e colaboradores (CAMPOS et al., 2004), mostrou que há uma correlação significativa entre a produção de polissacarídeos da cápsula bacteriana e a resistência à polimixina $\mathrm{B}$ por $K$. pneumoniae, de forma que cepas que produzem mais polissacarídeos tendem a ser mais resistentes. A absorção autopromovida de polimixina B também pode estar envolvida no mecanismo de resistência, o mesmo estudo mostrou que a lise da membrana externa de K. pneumoniae por SDS (do inglês, sodium-dodecyl sulfate) e por lisozima foi significativamente maior em cepas mutantes não-produtoras de cápsula quando comparadas com o modelo selvagem. Uma vez que há necessidade de interações eletrostáticas entre o antimicrobiano e a membrana externa das bactérias gram-negativas, esses achados indicam que a natureza da cápsula polissacarídica tem papel direto na resistência ao antimicrobiano. A cápsula também participa do mecanismo de escape do sistema complemento e da fagocitose, fato que corrobora com a maior virulência desses microorganismos capsulados. O uso de polimixina B provoca aumento da produção da cápsula polissacarídica por $K$. pneumoniae, sugerindo outro mecanismo de defesa desse patógeno frente à antibióticos e peptídeos antibacterianos.

\subsubsection{Terapia combinada}

A terapia antimicrobiana combinada de polimixinas com outros antimicrobianos é preferível, uma vez que essa prática potencialmente reduz a possibilidade do desenvolvimento da resistência durante o tratamento (Lee e Burgess, 2012). A ANVISA (Agência Nacional de Vigilância Sanitária), logo, recomenda a terapia empírica combinada para a suspeita de enterobactérias multirresistentes pela associação de polimixinas com tigeciclina, carbapenêmicos (meropenem ou doripenem) ou aminoglicosídeos (gentamicina ou amicacina) (NOTA TÉCNICA ANVISA No 01/2013). A abordagem clínica, no entanto, deve ser cuidadosa, uma vez que o sinergismo pode também levar à maior incidência de efeitos adversos, e, além do mais, carecem estudos clínicos controlados para avaliação de eficácia terapêutica (DUBROVSKAYA et al., 2013). Vários autores tem comparado a eficácia clínica de monoterapia ou terapia combinada no tratamento de infecções graves causadas por enterobactérias. Na revisão de Hirsh e Tam (HIRSCH; TAM, 2010) foram reunidos os resultados clínicos de 55 pacientes em 15 estudos, todos com infecção provocada por KPC$\mathrm{Kp}$, em que a associação de polimixinas com outro antimicrobiano apresentou $73 \%$ de sucesso terapêutico, ao passo que em monoterapia essa taxa caiu para 14\%. Em uma revisão sistemática realizada com artigos publicado entre 2001 e 2011, a taxa de falha no tratamento 
de KPC-Kp foi de $49 \%$ entre os pacientes que receberam polimixinas em monoterapia, enquanto que entre os pacientes com terapia combinada foi de $25 \%$ ( $p<0,001)$. O estudo concluiu que as associações de maior sucesso foram combinações de polimixinas com tigeciclina ou carbapenêmicos (LEE; BURGESS, 2012).

\subsubsection{Atual panorama da resistência a polimixinas}

Gales e colaboradores (GALES; JONES; SADER, 2006) realizaram uma avaliação global da atividade antimicrobiana de polimixina $\mathrm{B}$, por microdiluição em caldo, contra 54.731 bacilos Gram-negativos isolados entre 2001 e 2004, de diversos sítios de infecção, dentro do programa SENTRY de vigilância antimicrobiana. Esse programa permitiu a monitorização dos patógenos predominantes e dos seus padrões de resistência antimicrobiana em quatro regiões geográficas principais, incluindo Ásia e Pacífico, Europa, América Latina e América do Norte (EUA e Canadá). A atividade de polimixina B foi testada contra 40.923 isolados de enterobactérias, mostrando que as polimixinas apresentaram excelente atividade antimicrobiana contra Citrobacter (99,5\%), E. coli (99,5\%) e Klebsiella spp. (98,2\%). Da mesma forma, no estudo realizado mais recentemente pelo SENTRY (GALES; JONES; SADER, 2011), compilando os anos de 2006 e 2009, chegou-se a conclusão de que as polimixinas continuavam mantendo atividade satisfatória contra organismos gram-negativos. Em avaliação geral, para os 40.625 isolados de Acinetobacter spp, E. coli, Klebsiella spp., e Pseudomonas aeruginosa estudados, a sensibilidade às polimixinas foi superior à $98 \%$. Entretanto, entre isolados de $\mathrm{CRKp}, 12,0 \%$ apresentaram resistência à polimixina $\mathrm{B}$, enquanto na população geral esse valor foi de $1,4 \%$. O estudo também concluiu que nas regiões da América Latina, Ásia e Pacífico foi observada um aumento crescente da resistência às polimixinas, de 1,3\% em 2006 a 3,0\% em 2009 na América Latina, a qual pode ser explicada pelo aumento da prescrição desses antimicrobianos no tratamento de microrganismos gramnegativos multirresistentes. De fato, uma série de estudos reportam maior resistência às polimixinas entre isolados resistentes aos carbapenêmicos, particularmente em UTIs (AH; KIM; LEE, 2014), porém os resultados variam desde 4,4\% de resistência na China (CHEN et al., 2011) até $87,7 \%$ em estudo multicêntrico realizado na Hungria (porcentagem avaliada sobre pacientes e não isolados) (TÓTH et al., 2010).

A análise mais recente realizada pelo SENTRY (SADER et al., 2014), descreveu sensibilidade superior à $98 \%$ mesmo entre isolados de K. pneumoniae obtidos de cultura de pacientes internados em UTIs europeias. O estudo compreendeu 36 unidades hospitalares em 
nove países europeus, totalizando 1.320 isolados coletados entre 2009 e 2011. A análise acerca da resistência às polimixinas na Europa, no entanto, não pode ser generalizada uma vez que apenas alguns países apresentam situação endêmica da ocorrência de enterobactérias produtoras de carbapenemases, incluindo KPC (GLASNER et al., 2013). Entre esses países com preocupante disseminação endêmica de enterobactérias produtoras de KPC, estão Grécia (ANTONIADOU et al., 2007; ZARKOTOU et al., 2010) e Itália (GIACOBBE et al., 2015; GIANI et al., 2015b; MONACO et al., 2014). Em recente estudo multicêntrico italiano, dos 178 isolados de KPC-Kp coletados entre novembro de 2013 e abril de 2014, $43 \%$ eram resistentes à colistina (MONACO et al., 2014).

A emergência da resistência às polimixinas é uma ameaça ainda mais preocupante em pacientes com infecções provocadas por CRKp (CAPONE et al., 2013), e este pode ser o último passo em direção a uma epidemia de infecções intratáveis (VAN DUIN; DOI, 2015).

\subsubsection{Estudos brasileiros acerca da resistência às polimixinas}

No Brasil, Cavassim e colaboradores (CAVASSIM et al., 2011) avaliaram a susceptibilidade à polimixina $\mathrm{B}$, por microdiluição em caldo, de 44 isolados de KPC-Kp, identificados em cinco diferentes hospitais privados localizados em São Paulo e um hospital localizado em Porto Alegre. Foi verificado que 15,9\% dos isolados apresentavam resistência à polimixina B. Apesar do pequeno número de isolados estudados, o dado é extremamente preocupante, uma vez que as polimixinas são a principal opção terapêutica em pacientes infectados com cepas produtoras de KPC.

O estudo de Pereira (PEREIRA et al., 2011) encontrou três perfis clonais, obtidos por eletroforese em campo pulsado (PFGE, do inglês pulsed-field gel electrophoresis) entre 22 pacientes com CRKp, entre os quais a susceptibilidade total à polimixina $\mathrm{B}$ foi $73 \%$, porém um dos clones apresentou taxa de sensibilidade de apenas $20 \%$. Acredita-se que a presença de três diferentes clones seja em decorrência da admissão de pacientes colonizados em outras unidades de saúde.

Em uma análise retrospectiva realizada com 118 pacientes internados com infecção por enterobactérias produtoras de KPC entre outubro de 2009 e junho de 2013 em três hospitais da cidade de São Paulo (Hospital das Clínicas da Faculdade de Medicina da Universidade de São Paulo, Instituto do Câncer do Estado de São Paulo e Hospital Municipal José de Carvalho Florence), o tratamento com polimixinas foi associado à nefrotoxicidade em $39 \%$ dos pacientes e quatro pacientes que apresentaram neurotoxicidade também foram 
tratados com polimixinas. $\mathrm{Na}$ análise multivariada final, o uso de polimixinas foi associado, junto à idade avançada e falência renal, à mortalidade em até 30 dias de tratamento. O estudo concluiu que o maior risco de mortalidade associada ao tratamento com polimixinas não foi em decorrência da nefrotoxicidade como evento adverso isoladamente, mas sim à baixa eficácia do antimicrobiano devido ao uso de dosagens inadequadas e à resistência: 18 pacientes apresentaram CIM superior à 2,0 mg/L, porém esse dado não foi avaliado para todos os pacientes (DE OLIVEIRA et al., 2015).

\subsection{Considerações finais}

Conforme os relatos e disposições acima, entende-se a importância e o impacto clínico negativo da emergência da disseminação de microrganismos resistentes às polimixinas. Paralelamente, é necessária a geração de conhecimento através de estudos de eficácia clínica e de investigação laboratorial acerca do perfil de sensibilidade aos antimicrobianos para a determinação de parâmetros com os quais seja possível orientar a terapia empírica das infecções causadas por enterobactérias resistentes aos carbapenêmicos (ZAVASCKI et al., 2007). Assim, este estudo foi motivado pela observação do aumento das taxas de resistência às polimixinas em $K$. pneumoniae isoladas de pacientes internados em hospitais da grande área urbana de São Paulo, pela necessidade de determinação de pontos de corte para polimixina B e pela necessidade de avaliação da disseminação clonal e mecanismos de resistência às polimixinas nesses isolados. 


\section{OBJETIVOS}

\subsection{Objetivo geral}

Avaliar a relação genética, perfil de sensibilidade antimicrobiana e mecanismos de resistência às polimixinas em $K$. pneumoniae.

\subsection{Objetivos específicos}

Analisar estatisticamente, a partir do banco de dados do Fleury Medicina e Saúde, o perfil de sensibilidade de K. pneumoniae à polimixina $\mathrm{B}$, carbapenêmicos e antimicrobianos alternativos em hospitais da cidade de São Paulo.

Em isolados selecionados de $K$. pneumoniae resistentes à polimixina $\mathrm{B}$, determinar:

- A concentração inibitória mínima de polimixina B;

- A relação genética, por eletroforese em campo pulsado e sequenciamento de múltiplos loci;

- A presença e a sequencia completa dos genes $b l a_{K P C}$;

- A integridade do gene $m g r B$;

- A frequência do gene $m c r-1$. 


\section{MATERIAL E MÉTODOS}

A execução deste trabalho dividiu-se em duas partes principais. A primeira consistiu de levantamento de dados de culturas positivas para $K$. pneumoniae da rotina de pacientes hospitalizados em instituições atendidas pelo Fleury Medicina e Saúde (sessão 3.1). A segunda parte consistiu da confirmação das CIMs para polimixina B, avaliação da relação clonal por eletroforese em campos pulsados e sequenciamento de múltiplos loci (MLST, do inglês, multilocus sequence typing), avaliação da integridade do gene $\operatorname{mgrB}$ e da presença do gene $m c r-1$ por PCR entre isolados resistentes à polimixina $\mathrm{B}$ e carbapenêmicos (sessão 3.2).

\subsection{Análise estatística do banco de dados do Fleury Medicina e Saúde}

\subsubsection{Critérios de inclusão e exclusão}

Foi realizada por uma análise estatística retrospectiva a partir do banco de dados de antibiogramas realizados pelo Fleury Medicina e Saúde, os quais correspondem a pacientes hospitalizados durante o período de janeiro de 2011 a dezembro de 2015 em onze hospitais privados da Grande São Paulo.

Todos os isolados foram identificados ao nível de espécie por espectrometria de massa utilizando a sistemas Microflex ${ }^{\circledR}\left(\right.$ Bruker $\left.^{\circledR}\right)$ ou Vitek MS ${ }^{\circledR}$ (bioMérieux $\left.{ }^{\circledR}\right)$. Foram incluídos resultados positivos de análises de $K$. pneumoniae coletados a partir de culturas de sangue (hemocultura), trato respiratório (escarro, secreção traqueal, lavado bronco-alveolar) e outros locais de infecção diversos, tais como fragmentos de tecidos moles ou de feridas cirúrgicas. Isolados de uroculturas e de culturas de vigilância foram excluídos da análise, uma vez que o laboratório avaliou a CIM de polimixina B em isolados de infecções urinárias apenas nos casos de resistência aos carbapenêmicos e no mesmo período não avaliou a sensibilidade à polimixina $\mathrm{B}$ de isolados resistentes aos carbapenêmicos detectados em culturas de vigilância.

Os dados foram fornecidos pelo Fleury Medicina e Saúde em planilha de Excel ${ }^{\circledR}$ $\left(\right.$ Microsoft $\left.^{\circledR}\right)$, contendo a identificação numérica única para cada paciente, data de nascimento do paciente, data do exame, local de coleta da amostra clínica e o antibiograma. Dados duplicados de culturas de um mesmo paciente foram identificados e excluídos quando realizados com intervalo inferior a 90 dias. Isolados sem dados de sensibilidade a imipenem (IMP) e meropenem (MER), e que não estavam disponíveis na bacterioteca para novos ensaios, também foram excluídos. 


\subsubsection{Metodologia aplicada pelo Fleury Medicina e Saúde na determinação e}

interpretação da sensibilidade aos antimicrobianos

Os testes de susceptibilidade aos carbapenêmicos (IMP e MER), aminoglicosídeos e cloranfenicol foram realizados e interpretados de acordo com o documento do Clinical and Laboratory Standards Institute (CLSI, 2015). As CIMs para polimixina B e tigeciclina foram avaliadas por microdiluição não automatizada em caldo Mueller-Hinton cátion ajustado (CAMHB, do inglês, cation-adjusted Mueller-Hinton broth), segundo o documento do EUCAST (EUCAST, 2015) e CLSI (CLSI, 2015). A sensibilidade à fosfomicina foi determinada utilizando-se o Etest ${ }^{\circledR}$ (bioMérieux ${ }^{\circledR}$ ) de acordo com as instruções do fabricante. A CIM dos últimos antimicrobianos citados foi interpretada de acordo com o documento do EUCAST (EUCAST, 2015), à exceção da polimixina B, para a qual se utilizou a interpretação preconizada para colistina no mesmo documento. Os resultados só foram considerados quando os valores obtidos para E. coli ATCC 25922 estavam dentro dos limites aceitáveis (CLSI, 2015; EUCAST, 2015).

\subsubsection{Determinação do perfil de resistência aos carbapenêmicos e presença de} Klebsiella pneumoniae carbapenemase (KPC)

Para a determinação da resistência aos carbapenêmicos, foi realizada a triagem inicial com ertapenem através do método de Kirby-Bauer segundo as normas do EUCAST (EUCAST, 2015). Isolados cujo resultado fora interpretado como sensível foram considerados sensíveis a todos os carbapenêmicos. Os isolados resistentes ou com resistência intermediária ao ertapenem foram analisados também como descrito originalmente por Tsakris et al. (TSAKRIS et al., 2009), utilizando-se discos de MER e IMP com e sem ácido fenilborônico, cloxacilina ou EDTA, para a detecção da presença de KPC. Os mesmos isolados tiveram as CIMs para IMI e MER determinadas utilizando-se o Etest ${ }^{\circledR}\left(\right.$ bioMérieux $\left.^{\circledR}\right)$.

\subsubsection{Análise estatística}

Todas as análises estatísticas foram conduzidas usando SAS Studio 3.4 (SAS Institute, Inc., Cary, NC, EUA). A significância estatística da tendência nas taxas de resistência foi avaliada usando o teste $\chi 2$, em que foram considerados significativos os valores de $p<0,05$. 


\subsection{Avaliação da relação clonal e mecanismo de resistência entre isolados de}

K. pneumoniae resistentes à polimixina $\mathrm{B}$ obtidos de pacientes hospitalizados

\subsubsection{Seleção, isolamento e armazenamento de bactérias}

Neste trabalho foram utilizadas bactérias obtidas de culturas oriundas de amostras de pacientes hospitalizados em 10 instituições da Grande São Paulo, totalizando cerca de 3 mil leitos. Visando evidenciar o cenário epidemiológico mais atual, foram utilizados apenas isolados resistentes à polimixina B, detectados durante os anos de 2014 e 2015, para os ensaios de PFGE, PCR e MLST. Foram analisados, utilizando-se essas metodologias, isolados de 60 pacientes distintos dos diferentes hospitais. Os isolados foram repicados em ágar MacConkey e em seguida incubados a $37^{\circ} \mathrm{C}$ por 18 horas. As culturas foram avaliadas quanto à pureza e fenótipo colonial. As bactérias foram novamente repicadas em ágar Luria Broth (LB) para em seguida serem armazenadas em caldo LB acrescido de $15 \%$ de glicerol e estocadas a $-80^{\circ} \mathrm{C}$. A identificação da espécie foi reconfirmada por espectrometria de massas $\left(\right.$ Vitek $\left.\mathrm{MS}^{\circledR}\right)$.

\subsubsection{Teste de sensibilidade à polimixina $B$}

Na preparação dos isolados para a realização do teste de sensibilidade, as bactérias armazenadas a $-80^{\circ} \mathrm{C}$ foram descongeladas, repicadas em ágar $\mathrm{LB}$ e incubadas a $37^{\circ} \mathrm{C}$ por 18 horas. Em seguida foram preparadas suspensões bacterianas em salina com turbidez equivalente ao padrão 0,5 da escala de McFarland.

Foi utilizado o teste da microdiluição em caldo para determinação das CIM para polimixina B entre os isolados de $K$. pneumoniae em conformidade com a recomendação do grupo de trabalho do CLSI e EUCAST (EUCAST, 2016). Na preparação das placas de 96 poços, foi utilizado CAMHB (Becton-Dickinson ${ }^{\circledR}$ ), contendo as concentrações de polimixina B de 0,06 a $64 \mathrm{mg} / \mathrm{L}$, além do controle de crescimento sem antimicrobiano. O volume utilizado na preparação da diluição de antimicrobiano para cada poço foi de $50 \mu \mathrm{L}$. As placas foram armazenadas à temperatura de $-80^{\circ} \mathrm{C}$ até o momento do uso. Para a inoculação das placas, após descongelamento, adicionou-se $50 \mu \mathrm{L}$ de caldo CAMHB contendo suspensão bacteriana, com turbidez equivalente ao padrão 0,5 da escala de MacFarland, diluída na proporção de 1/100. As concentrações finais do antimicrobiano foram de 0,03 a $32 \mathrm{mg} / \mathrm{L}$ em volume de $100 \mu \mathrm{L}$. As placas foram incubadas à $37^{\circ} \mathrm{C}$ por 18 a 24 horas em ar ambiente. Os 
resultados das CIM de polimixina B foram interpretados seguindo critérios estabelecidos para colistina pelo EUCAST (EUCAST, 2015), que estabelece sensibilidade quando há inibição do crescimento bacteriano em concentrações $\leq 2 \mathrm{mg} / \mathrm{L}$ e resistência em concentrações $>2 \mathrm{mg} / \mathrm{L}$. Em todas as análises cada isolado foi testado em duplicata e foi utilizada a cepa $E$. coli ATCC 25922 como controle, cujo intervalo aceitável é de 0,25 a 2 mg/L (CLSI, 2015; JONES; ANDEREGG; SWENSON, 2005).

\subsubsection{Tipagem molecular por eletroforese em campo pulsado (PFGE)}

Os perfis de macrorrestrição do DNA genômico dos 60 isolados de K. pneumoniae foram analisados por PFGE. Os blocos de agarose contendo DNA bacteriano foram preparados segundo o protocolo de Ribot e colaboradores (RIBOT et al., 2006). Preparou-se uma suspensão com turbidez equivalente ao padrão 3,8 a 4,2 da escala de McFarland, em tampão de lise celular (100mM Tris com 100mM EDTA), a partir de crescimento bacteriano obtido em ágar LB . A suspensão $(300 \mu \mathrm{L})$ foi adicionada a $15 \mu \mathrm{L}$ de proteinase $\mathrm{K}$ (20 $\mathrm{mg} / \mathrm{ml}$ ), homogeneizada e mantida em banho seco a $60^{\circ} \mathrm{C}$. Em seguida foram adicionados 300 $\mu \mathrm{L}$ agarose a $1 \%$ e a solução foi transferida para molde plástico e mantida em temperatura ambiente por 15 a 30 minutos, até a completa solidificação. Em seguida os blocos, foram transferidos para uma placa de cultura de células de 12 poços contendo $2 \mathrm{~mL}$ de tampão de lise celular e $10 \mu \mathrm{L}$ de proteinase $\mathrm{K}(20 \mathrm{mg} / \mathrm{mL})$. A placa com os blocos foi e incubada à $54^{\circ} \mathrm{C}$ em agitação de 160 rpm. Após 2 horas, os blocos foram lavados pelo menos 4 vezes com água ultrapura estéril a $50^{\circ} \mathrm{C}$ a cada 15 minutos sob agitação de $160 \mathrm{rpm}$. Os blocos foram estocados a $4^{\circ} \mathrm{C}$ em tampão TE (Tris $1 \mathrm{M}$, EDTA 0,5M, pH 8,0). Para a digestão do DNA, os blocos foram previamente lavados três vezes com tampão TE à $37^{\circ} \mathrm{C}$. A digestão foi realizada utilizando-se $6 \mathrm{U}$ daenzima de restrição $X b a I^{\circledR}$ (Invitrogen ${ }^{\circledR}$ ), para cada reação, com volume final de $100 \mu \mathrm{L}$. As reações foram incubadas a $37^{\circ} \mathrm{C}$ por 18 horas. Os blocos foram submetidos à eletroforese em campo pulsado utilizando-se o sistema CHEF-DRIII (Bio$\left.\operatorname{Rad}^{\circledR}\right)$, cujas condições de corrida foram: tempo do pulso inicial: 2,1 segundos; tempo do pulso final: 63,8 segundos; voltagem: $6 \mathrm{~V}$, ângulo: $120^{\circ}$; tempo total da corrida: 19 horas; $14^{\circ} \mathrm{C}$. Após o término da eletroforese, o gel foi imerso em solução $3 \mathrm{X}$ de $\operatorname{GelRed}^{\circledR}\left(\right.$ Biotium $\left.^{\circledR}\right)$ por 30 minutos, sendo então fotografado pelo sistema AlphaImager ${ }^{\circledR}$ (Alpha Innotech ${ }^{\circledR}$ ) sob luz ultravioleta. Os perfis eletroforéticos de macrorrestrição foram analisados visualmente segundo critérios estabelecidos por Tenover e colaboradores (TENOVER et al., 1995) e também com auxílio do programa GelJ (HERAS et al., 2015) através da execução de um 
dendograma. A similaridade genômica dos isolados foi determinada pelo coeficiente Dice e o dendograma construído segundo o método UPGMA (do inglês, Unweighted Pair Group Method with Arithmetic Mean) com tolerância de 1,25\%.

\subsubsection{Tipagem por sequenciamento de múltiplos loci (MLST)}

A MLST foi realizada de acordo com o método previamente descrito (DIANCOURT et al., 2005) em 12 isolados, cuja seleção foi baseada na análise dos perfis eletroforéticos de macrorrestrição obtidos por PFGE. Sete genes constitutivos (gapA, mdh, pgi, rpoB, infB, phoE, e tonB) foram amplificadas para cada isolado por PCR, cujos iniciadores utilizados e condições de reação estão detalhadas na tabela 1 .

Os amplicons foram analisados por eletroforese em gel de agarose a $1 \%$ e subsequentemente purificados com Illustra GFX PCR DNA and Gel Band Purification Kit ${ }^{\circledR}$ (GE Healthcare Life Sciences ${ }^{\circledR}$ ) e sequenciados utilizando-se método do BigDye Terminator versão 3.1 no aparelho 3130XL Genetic Analyzer ${ }^{\circledR}$ (Applied Biosystems ${ }^{\circledR}$ ), de acordo com recomendações dos fabricantes. Os iniciadores utilizados no sequenciamento, bem como as condições de reação, estão especificados na tabela 2. As sequencias consenso foram montadas utilizando-se o programa DNABaser ${ }^{\circledR}$ v. 3.4.5 (Heracle Biosoft ${ }^{\circledR}$ ).

As sequencias consenso obtidas foram comparadas com sequências disponíveis no banco de dados de MLST para $K$. pneumoniae fornecido pelo Instituto Pasteur (http://bigsdb.web.pasteur.fr/klebsiella/klebsiella.html), de modo a se obter a classificação do MLST.

\subsubsection{Amplificação e análise do gene blaKPC}

Para a determinação da sequência de nucleotídeos completa do gene bla KPC $_{\text {foram }}$ realizadas reações de PCR em 11 isolados entre aqueles que foram tipados por MLST como anteriormente descrito (RIBEIRO et al., 2012), exceto pelo fato de que os iniciadores utilizados foram desenhados para este estudo e estão especificados na tabela 1 juntamente às condições de reação. Os amplicons foram subsequentemente analisados por eletroforese em gel de agarose a $1 \%$, purificados e sequenciados da mesma forma especificada na sessão 3.2.4 Os iniciadores utilizados no sequenciamento, bem como as condições de reação, estão especificados na tabela 2 .

As sequencias consenso foram montadas e traduzidas em aminoácidos utilizando o 
software DNABaser ${ }^{\circledR}$ v. 3.4.5 (Heracle Biosoft $^{\circledR}$ ) para em seguida serem comparadas com as sequências disponíveis no GenBank ${ }^{\circledR}$ através do software BLAST.

\subsubsection{Amplificação e análise do gene $m g r B$}

Para a avaliação da integridade do gene $\operatorname{mgrB}$, foi realizada amplificação do mesmo por PCR, cujos iniciadores utilizados e condições de reação estão detalhadas na tabela 1. Os amplicons foram subsequentemente analisados por eletroforese em gel de agarose a $1 \%$, purificados e sequenciados da mesma forma especificada na sessão 3.2.4. Os iniciadores utilizados no sequenciamento, bem como as condições de reação, estão especificados na tabela 2 .

As sequências consenso obtidas foram comparadas com sequências disponíveis no GenBank $^{\circledR}$ utilizando-se o programa BLAST ${ }^{\circledR}$, e também na plataforma ISfinder $^{\circledR}$ (https://www-is.biotoul.fr/) para pesquisa de sequências de inserção.

\subsubsection{Amplificação do gene $m c r-1$}

Para a avaliação da presença do gene $m c r-1$, foi realizada reação de PCR, cujos iniciadores utilizados e condições de reação estão detalhadas na tabela 1. Os amplicons foram subsequentemente analisados por eletroforese em gel de agarose a $1 \%$. A cepa de E. coli utilizada como controle positivo em todas as reações foi gentilmente cedida pelo Professor Nilton Lincopan. 


\section{Tabela 1. Lista de iniciadores utilizados e condições das reações de PCR}

\begin{tabular}{|c|c|c|c|c|}
\hline Gene & & Sequência $\left(5^{\prime}-3^{\prime}\right)$ & $\begin{array}{c}\text { Condições do ciclo } \\
\text { (temperatura/tempo) } \times \mathrm{N}^{2} \\
\end{array}$ & Referência \\
\hline \multirow{2}{*}{ gapA } & $\mathrm{F}^{1}$ & GTTTTCCCAGTCACGACGTTGTATGAAATATGACTCCACTCACGG & \multirow{14}{*}{$\left(94^{\circ} \mathrm{C} / 30^{\prime \prime}-50^{\circ} \mathrm{C} / 1^{\prime}-72^{\circ} \mathrm{C} / 1^{\prime}\right) \times 35$} & \multirow{14}{*}{$\begin{array}{l}\text { (DIANCOURT et al., } \\
\text { 2005) }\end{array}$} \\
\hline & $\mathrm{R}^{2}$ & TTGTGAGCGGATAACAATTTCCTTCAGAAGCGGCTTTGATGGCTT & & \\
\hline \multirow{2}{*}{$m d h$} & F & GTTTTCCCAGTCACGACGTTGTACCCAACTCGCTTCAGGTTCAG & & \\
\hline & $\mathrm{R}$ & TTGTGAGCGGATAACAATTTCCCGTTTTTCCCCAGCAGCAG & & \\
\hline \multirow{2}{*}{$p g i$} & $\mathrm{~F}$ & GTTTTCCCAGTCACGACGTTGTAGAGAAAAACCTGCCTGTACTGCTGGC & & \\
\hline & $\mathrm{R}$ & TTGTGAGCGGATAACAATTTCCGCGCCACGCTTTATAGCGGTTAAT & & \\
\hline \multirow{2}{*}{$r p o B$} & $\mathrm{~F}$ & GTTTTCCCAGTCACGACGTTGTAGGCGAAATGGCWGAGAACCA & & \\
\hline & $\mathrm{R}$ & TTGTGAGCGGATAACAATTTCGAGTCTTCGAAGTTGTAACC & & \\
\hline \multirow{2}{*}{$\operatorname{infB}$} & $\mathrm{F}$ & GTTTTCCCAGTCACGACGTTGTACTCGCTGCTGGACTATATTCG & & \\
\hline & $\mathrm{R}$ & TTGTGAGCGGATAACAATTTCCGCTTTCAGCTCAAGAACTTC & & \\
\hline \multirow{2}{*}{ phoE } & $\mathrm{F}$ & GTTTTCCCAGTCACGACGTTGTAACCTACCGCAACACCGACTTCTTCGG & & \\
\hline & $\mathrm{R}$ & TTGTGAGCGGATAACAATTTCTGATCAGAACTGGTAGGTGAT & & \\
\hline \multirow{2}{*}{$\operatorname{ton} B$} & $\mathrm{~F}$ & GTTTTCCCAGTCACGACGTTGTACTTTATACCTCGGTACATCAGGTT & & \\
\hline & $\mathrm{R}$ & TTGTGAGCGGATAACAATTTCATTCGCCGGCTGRGCRGAGAG & & \\
\hline \multirow{2}{*}{ 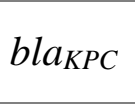 } & $\mathrm{F}$ & CTAGCTCCACCTTCAAACAAGGA & \multirow{2}{*}{$\left(94^{\circ} \mathrm{C} / 30^{\prime \prime}-50^{\circ} \mathrm{C} / 1^{\prime}-72^{\circ} \mathrm{C} / 1^{\prime}\right) \times 35$} & \multirow{2}{*}{$\begin{array}{c}\text { Iniciadores desenhados } \\
\text { neste estudo }\end{array}$} \\
\hline & $\mathrm{R}$ & TGGGTGGGCCAATAGATGAT & & \\
\hline \multirow{2}{*}{$m g r B$} & $\mathrm{~F}$ & AAGGCGTTCATTCTACCACC & \multirow{2}{*}{$\left(95^{\circ} \mathrm{C} / 30^{\prime \prime}-54^{\circ} \mathrm{C} / 30^{\prime \prime}-72^{\circ} \mathrm{C} / 1^{\prime} 45^{\prime \prime}\right) \times 35$} & \multirow{2}{*}{$\begin{array}{l}\text { (CANNATELLI et al., } \\
\text { 2013) }\end{array}$} \\
\hline & $\mathrm{R}$ & TTAAGAAGGCCGTGCTATCC & & \\
\hline \multirow{2}{*}{$m c r-1$} & $\mathrm{~F}$ & CGGTCAGTCCGTTTGTTC & \multirow{2}{*}{$\left(95^{\circ} \mathrm{C} / 30^{\prime \prime}-55^{\circ} \mathrm{C} / 30^{\prime \prime}-72^{\circ} \mathrm{C} / 30^{\prime \prime}\right) \times 35$} & \multirow{2}{*}{ (LIU et al., 2015) } \\
\hline & $\mathrm{R}$ & CTTGGTCGGTCTGTA GGG & & \\
\hline
\end{tabular}

${ }^{1}$ Iniciador forward.

${ }^{2}$ Iniciador reverse.

${ }^{3}$ Todas as PCR incluem uma etapa inicial de desnaturação à $94^{\circ} \mathrm{C}$ por 5 minutos e após os ciclos de desnaturação, anelamento dos iniciadores e amplificação acrescenta-se uma única etapa final de extensão à $72^{\circ} \mathrm{C}$ por 5 minutos.

${ }^{4}$ Número de repetições do ciclo de desnaturação, anelamento dos iniciadores e amplificação. 
Tabela 2. Lista de iniciadores utilizados e condições da reação de sequenciamento com Big Dye Terminator ${ }^{\circledR}$

\begin{tabular}{|c|c|c|c|c|}
\hline Gene & & Sequência (5'-3’) & $\begin{array}{c}\text { Condições do ciclo } \\
\text { (temperatura/tempo) } x \mathrm{~N}^{3}\end{array}$ & Referência \\
\hline \multirow{2}{*}{$\begin{array}{c}\text { gapA, mdh, pgi, rpoB, } \\
\text { inf } B, \text { phoE, tonB }\end{array}$} & $\mathrm{F}^{1}$ & " GTTTTCCCAGTCACGACGTTGTA & \multirow{6}{*}{$\begin{array}{c}96^{\circ} \mathrm{C} / 5 \\
+ \\
+ \\
\left(94^{\circ} \mathrm{C} / 30^{\prime \prime}-50^{\circ} \mathrm{C} / 1^{\prime}-72^{\circ} \mathrm{C} / 1^{\prime}\right) \times 35 \\
+ \\
60^{\circ} \mathrm{C} / 7\end{array}$} & (DIANCOURT et al., \\
\hline & $\mathrm{R}^{2}$ & TTGTGAGCGGATAACAATTTC & & 2005) \\
\hline \multirow{2}{*}{$b l a_{K P C}$} & $\mathrm{~F}$ & GCCGCCAATTTGTTGCTGAA & & Iniciadores desenhados \\
\hline & $\mathrm{R}$ & GCAGAGCCCAGTGTCAGTTT & & neste estudo \\
\hline \multirow{2}{*}{$\operatorname{mgr} B$} & $\mathrm{~F}$ & AAGGCGTTCATTCTACCACC & & (CANNATELLI et al., \\
\hline & $\mathrm{R}$ & TTAAGAAGGCCGTGCTATCC & & 2013) \\
\hline
\end{tabular}




\section{RESULTADOS}

\subsection{Análise estatística do banco de dados do Fleury Medicina e Saúde}

Um total de 3.085 isolados de $K$. pneumoniae foram incluídos neste estudo após a exclusão de duplicatas $(\mathrm{N}=165)$ de um mesmo paciente. Um total de 76 isolados de $K$. pneumoniae não-duplicados e para os quais não estavam disponíveis dados do teste de susceptibilidade aos carbapenêmicos (e que não poderiam ser obtidos de um novo ensaio) também foram excluídos da análise. O número de isolados recuperados a cada ano aumentou gradativamente ao longo do período de estudo e foram mais frequentemente obtidos a partir de culturas de sangue (tabela 3 ).

Houve um aumento estatisticamente significativo na resistência aos carbapenêmicos (p $<0,001$ ), variando de 6,8\% em 2011 para 35,5\% em 2015 (figura 4). Durante o último ano de análise, KPC foi detectada em 96,2\% dos CRKP.

Tabela 3. Características demográficas dos isolados de Klebsiella pneumoniae incluídos na análise estatística da base de dados do Fleury Medicina e Saúde (2011 a 2015)

\begin{tabular}{ll}
\hline Característica & $\mathrm{N}^{1}\left(\%^{2}\right)$ \\
\hline \hline Ano & \\
2011 & $468(15,2)$ \\
2012 & $518(16,8)$ \\
2013 & $629(20,4)$ \\
2014 & $662(21,5)$ \\
2015 & $808(26,2)$ \\
\hline
\end{tabular}

\section{Isolados excluídos do estudo}

Duplicatas 165

Sem teste de susceptibilidade aos carbapenêmicos $\quad 76$

\section{Sítio de isolamento da amostra}

Sangue

Trato respiratório

Outros sítios ${ }^{3}$

$$
1.055(34,2)
$$

Total de isolados incluídos no estudo: 3.085

\footnotetext{
${ }^{1}$ Número de isolados.

${ }^{2}$ Porcentagem sobre o número total de isolados incluídos no estudo.

${ }^{3}$ À exceção de urina e amostras de vigilância.
} 


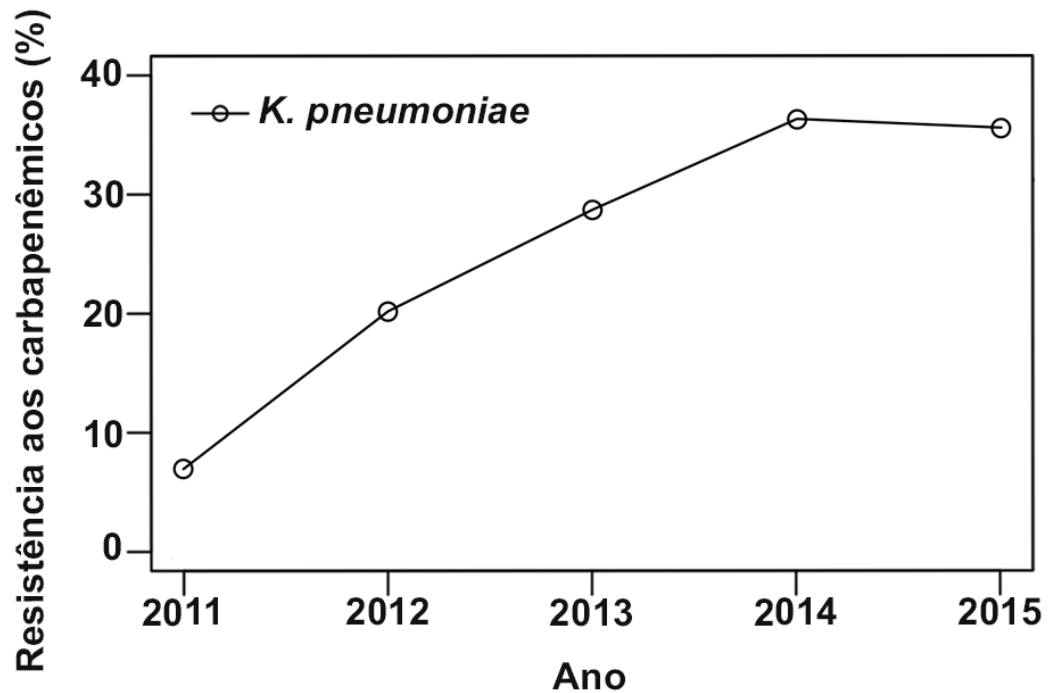

Figura 4. Evolução da resistência aos carbapenêmicos por Klebsiella pneumoniae isolados de pacientes internados em hospitais privados da Grande São Paulo, 2011-2015. $\mathrm{N}=3.085$. Tendência anual estatisticamente significativa $(\mathrm{p}<0,001)$.

Para a avaliação do perfil de resistência à polimixina $\mathrm{B}$ foi necessario restringir a análise dos isolados totais de K. pneumoniae e daqueles sensíveis aos carbapenêmicos que foram obtidos até 30 de junho de 2014, uma vez que a partir de 1 de julho de 2015, o laboratório Fleury Medicina e Saúde determinou a CIM de de polimixina B apenas para isolados resistentes aos carbapenêmicos. Dessa forma, o número total de de isolados até 30 de junho de 2014 foi de 1.947. Esta medida foi necessária para que se evitasse o viés de análise. Também para essa análise, os isolados foram divididos em dois grupos de acordo com o perfil de sensibilidade aos carbapenêmicos, sendo que o grupo sensível reuniu 1.511 isolados. Para os isolados resistentes aos carbapenêmicos a estatística se manteve até 31 de dezembro de 2015, reunindo 813 isolados.

A distribuição da CIM de polimixina B entre todos os isolados de $K$. pneumoniae evidenciou uma distribuição bimodal, de forma que a CIM de $2 \mathrm{mg} / \mathrm{L}$ diferencia claramente estas duas populações (figura 5). Esse valor coincide com a CIM de colistina recomendado pelo EUCAST (EUCAST, 2015) para Enterobacteriaceae e, por conseguinte, assumiu-se esse valor como o ponto crítico de susceptibilidade para a polimixina B. Dessa forma, 3,6\% do número total de isolados foram interpretados como resistentes, enquanto esta proporção entre CRKp foi de $22,5 \%$. 


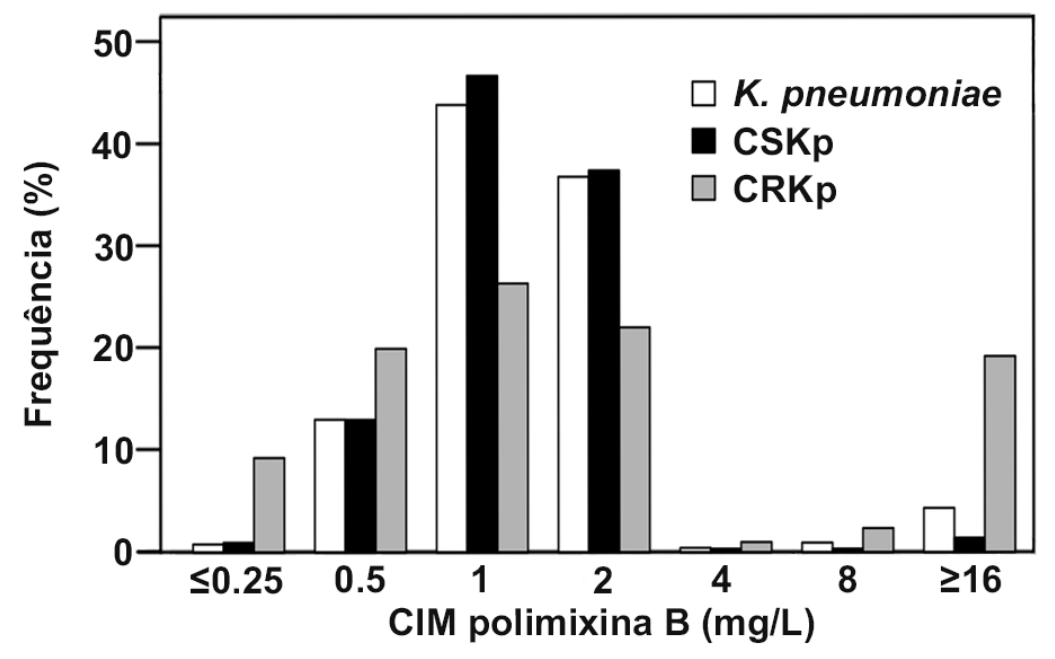

Figura 5. Distribuição das concentrações inibitórias mínimas de polimixina $B$ entre isolados de Klebsiella pneumoniae estratificadas por susceptibilidade aos carbapenêmicos. Total de K. pneumoniae (N=1.947). CRKp: K. pneumoniae resistente aos carbapenêmicos ( $\mathrm{N}=813)$. CSKp: K. pneumoniae sensíveis aos carbapenêmicos $(\mathrm{N}=1.511)$.

Quando os valores CIM foram estratificados por ano e por perfil de resistência aos carbapenêmicos, observou-se um aumento estatisticamente significativo ( $\mathrm{p}<0,001)$ na tendência anual da resistência à polimixina $\mathrm{B}$ por CRKp. A taxa de resistência foi de $0 \%$ em 2011, 24,8\% em 2014 (até 30 de junho) e 27,1\% em 2015 (figura 6). Em CSKp essas taxas variaram de 0,7\% em 2011 para 3,9\% em 2014 (até 30 de junho, p = 0,002). Não foram observadas diferenças estatisticamente significativas nas taxas de resistência aos carbapenêmicos e à polimixina $\mathrm{B}$ entre os tipos de local de infecção.

Os perfis de susceptibilidade a outros antimicrobianos não- $\beta$-lactâmicos entre isolados de CRKp e CRKp resistente à polimixina B (CPRKp) estão apresentados na tabela 4. Amicacina e tigeciclina foram os compostos mais ativos, ao passo que o ciprofloxacino, trimetoprim-sulfametoxazol, cloranfenicol e fosfomicina foram os menos ativos. Um total de 30 isolados CPRKp (16,4\%) foram resistentes a aminoglicosídeos, sendo que a proporção desses isolados panresistentes durante o período observado foi de 0\% em 2011 e 2012, 16,3\% em 2013, 8,8\% em 2014 e 24,7\% em 2015 ( $p=0,0457$ ). 


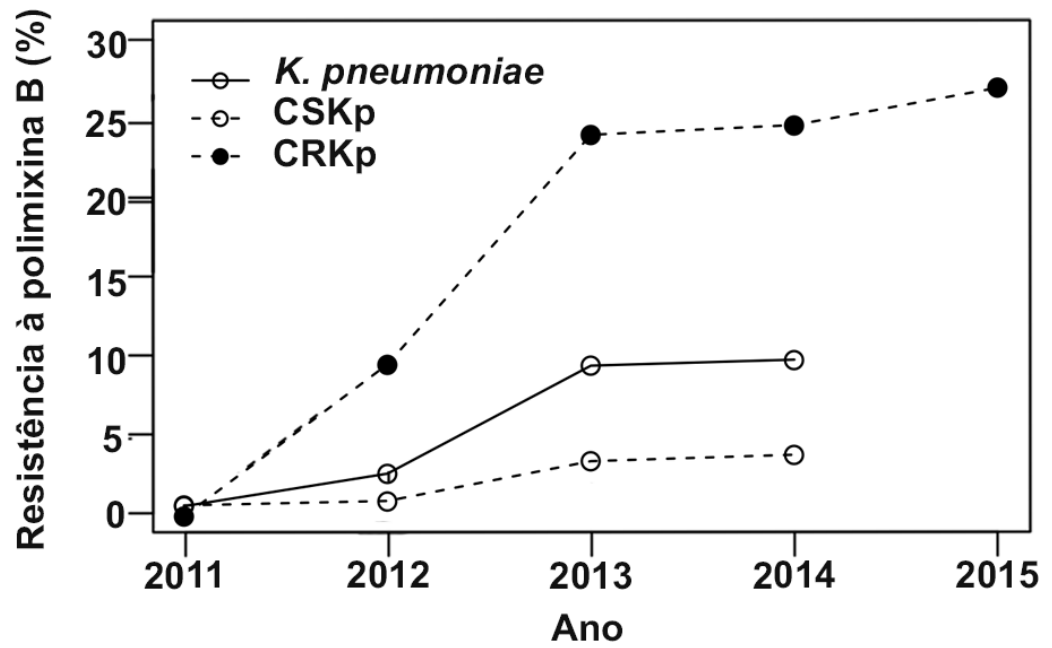

Figura 6. Evolução da resistência à polimixina $\mathrm{B}$ entre o total de isolados de Klebsiella pneumoniae e segundo a sensibilidade aos carbapenêmicos. Todas as tendências foram estatisticamente significativas: $K$. pneumoniae ( $\mathrm{p}<0,001)$, CSKp ( $=0,004)$ e CRKp ( $\mathrm{p}=0,003)$. K. pneumoniae - total de isolados de janeiro de 2011 a junho de $2014(\mathrm{n}=1.947)$. CSKp: K. pneumoniae susceptível aos carbapenêmicos de janeiro de 2011 a junho de 2014 (n=1.511). CRKp: K. pneumoniae resistente aos carbapenêmicos janeiro de 2011 a dezembro de $2015(\mathrm{n}=813)$.

Tabela 4. Susceptibilidade a antimicrobianos alternativos em Klebsiella pneumoniae estratificado por resistência aos carbapenêmicos e polimixina B (2011 a 2015).

\begin{tabular}{lcc}
\hline Antimicrobiano & $\begin{array}{c}\mathrm{CRKp}^{1} \\
\%^{3}\left(\mathrm{~N}^{4}\right)\end{array}$ & $\begin{array}{c}\mathrm{CPRKp} \\
\%(\mathrm{~N})\end{array}$ \\
\hline \hline Amicacina & $79,9(841)$ & $73,8(183)$ \\
Cloranfenicol & $23,8(530)$ & $41,6(137)$ \\
Fosfomicina & $27,9(258)$ & $81,6(60)$ \\
Gentamicina & $50,9(839)$ & $58,2(182)$ \\
Tigeciclina & $72,2(468)$ & $69,4(111)$ \\
\hline
\end{tabular}

${ }^{1} \mathrm{CRKp:}$ K. pneumoniae resistente aos carbapenêmicos.

${ }^{2}$ CPRKp: K. pneumoniae resistente aos carbapenêmicos e à polimixina $\mathrm{B}$.

${ }^{3}$ Porcentagem de susceptibilidade.

${ }^{4}$ Número de isolados testados para cada antimicrobiano.

\subsection{Análise da relação clonal entre isolados de Klebsiella pneumoniae}

Foram selecionados 60 CPRKp obtidos nos anos de 2014 e 2015 de amostras clínicas de pacientes hospitalizados para análise da relação clonal através de PFGE. A idade desses pacientes variou de um mês e 20 dias até 96 anos; mais de $80 \%$ possuíam idade acima dos 50 
anos e $43 \%$ eram do sexo feminino. Um total de sete isolados foram obtidos de pacientes internados em dois hospitais públicos distintos (hospitais "A" e "B", na Figura 4.4), enquanto 50 isolados foram obtidos de pacientes internados em oito diferentes hospitais privados (hospitais "C" a "J") e os demais 3 isolados foram obtidos de pacientes em atendimento domiciliar (figura 7).

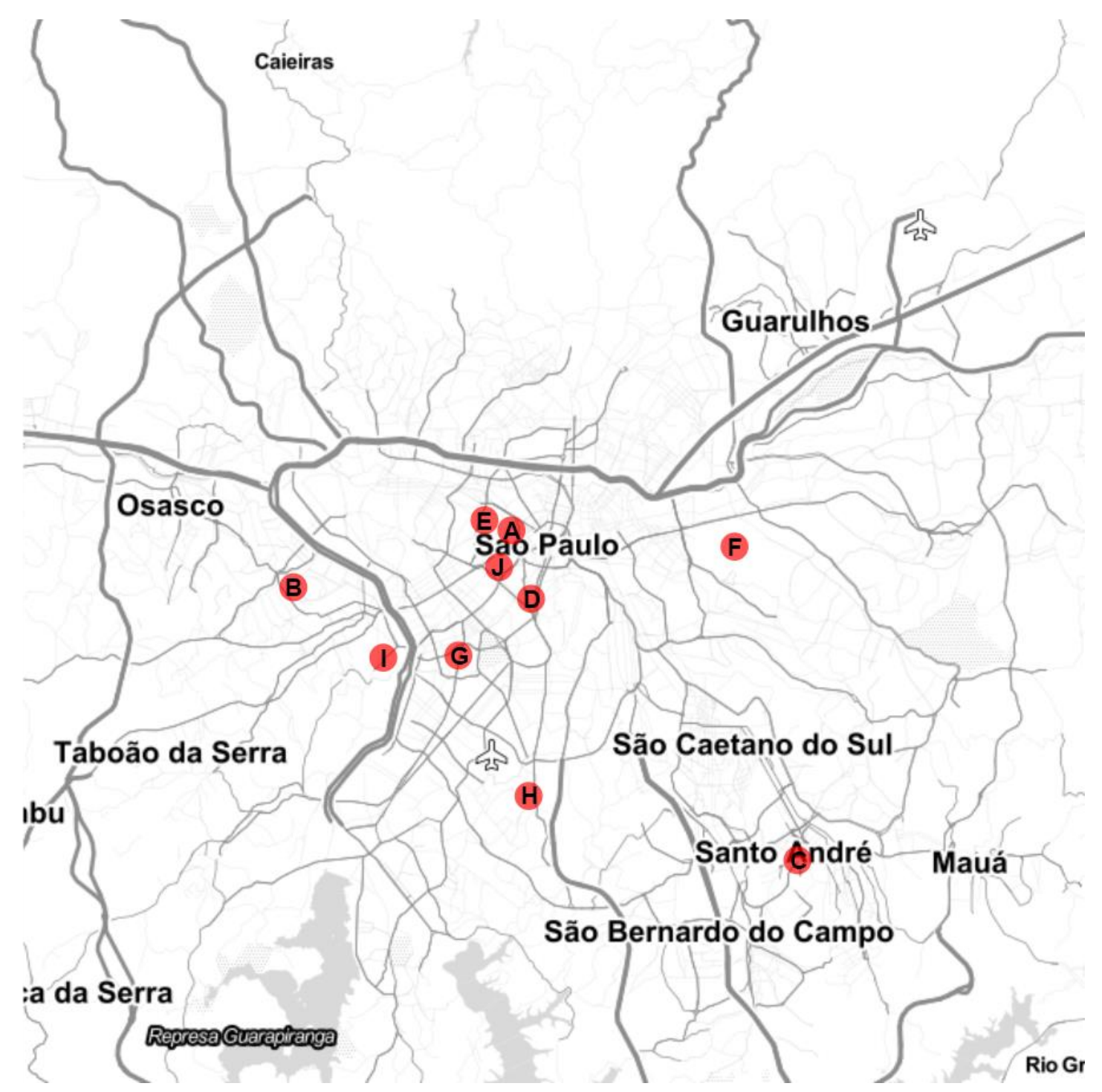

Figura 7. Mapa representativo da distribuição dos 10 hospitais em que foram obtidos os 60 isolados de Klebsiella pneumoniae deste estudo. Os círculos em vermelho indicam a localização de cada hospital, diferenciados pelas letras de "A" a "J".

Quando os perfis eletroforéticos de macrorrestrição obtidos nos géis de PFGE (figura 8) foram comparados, a maior parte dos isolados obteve pares com até três diferenças de banda por comparação visual, sendo assim interpretados como estreitamente relacionados e possivelmente parte de um mesmo grupo clonal. Isolados indistinguíveis por comparação 
visual foram categorizados como parte de um mesmo grupo clonal. Considerou-se também o índice de similaridade de Dice superior a $80 \%$ entre os perfis quando agrupados e comparados no dendograma, mostrado na Figura 9. Através desses critérios, foram identificados dois grandes grupos clonais denominados CPRKp1 (N=31) e CPRKp2 (N=17). A análise por MLST em 11 isolados representativos desses dois grupos maiores mostou que o grupo CPRKp1 pertence ao grupo clonal ST11 (do inglês, sequencing type), enquanto CPRKP2 pertence a ST437, ambos STs pertencentes ao complexo clonal 258 (CC258). Todos os 12 isolados tipados pelo MLST possuíam o gene bla $a_{\mathrm{KPC}-2}$, evidenciado através de sequenciamento completo do gene.

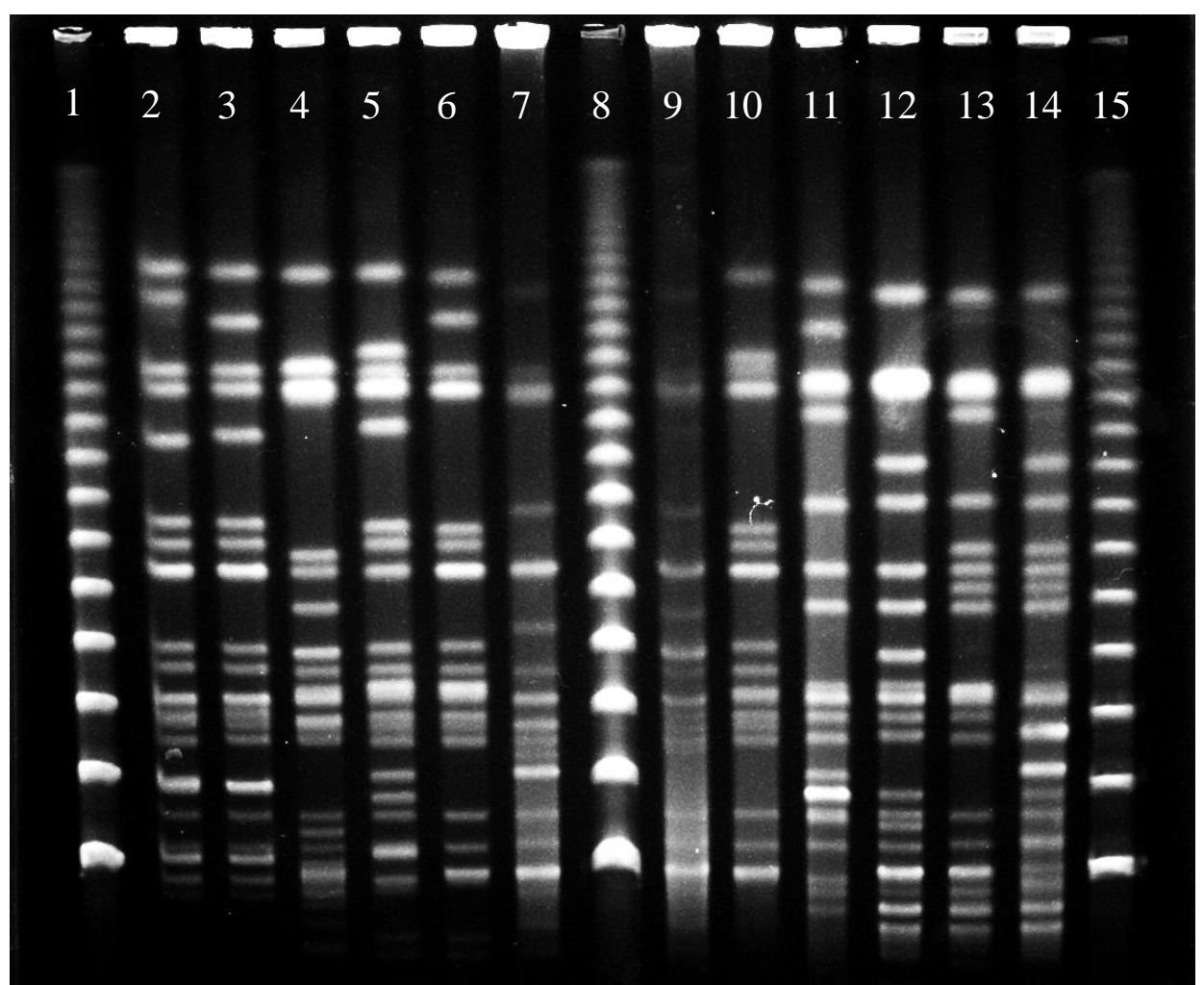

Figura 8. Foto de gel obtido por eletroforese de campo pulsado (PFGE) para exemplificação. As canaletas 1, 7 e 15 contém o padrão molecular Lambda Ladder PFG Marker $^{\circledR}$ (New England Biolabs ${ }^{\circledR}$ ), e nas demais canaletas observam-se os perfis de macrorrestrição de DNA de isolados de Klebsiella pneumoniae obtidos pela digestão com XbaI. 


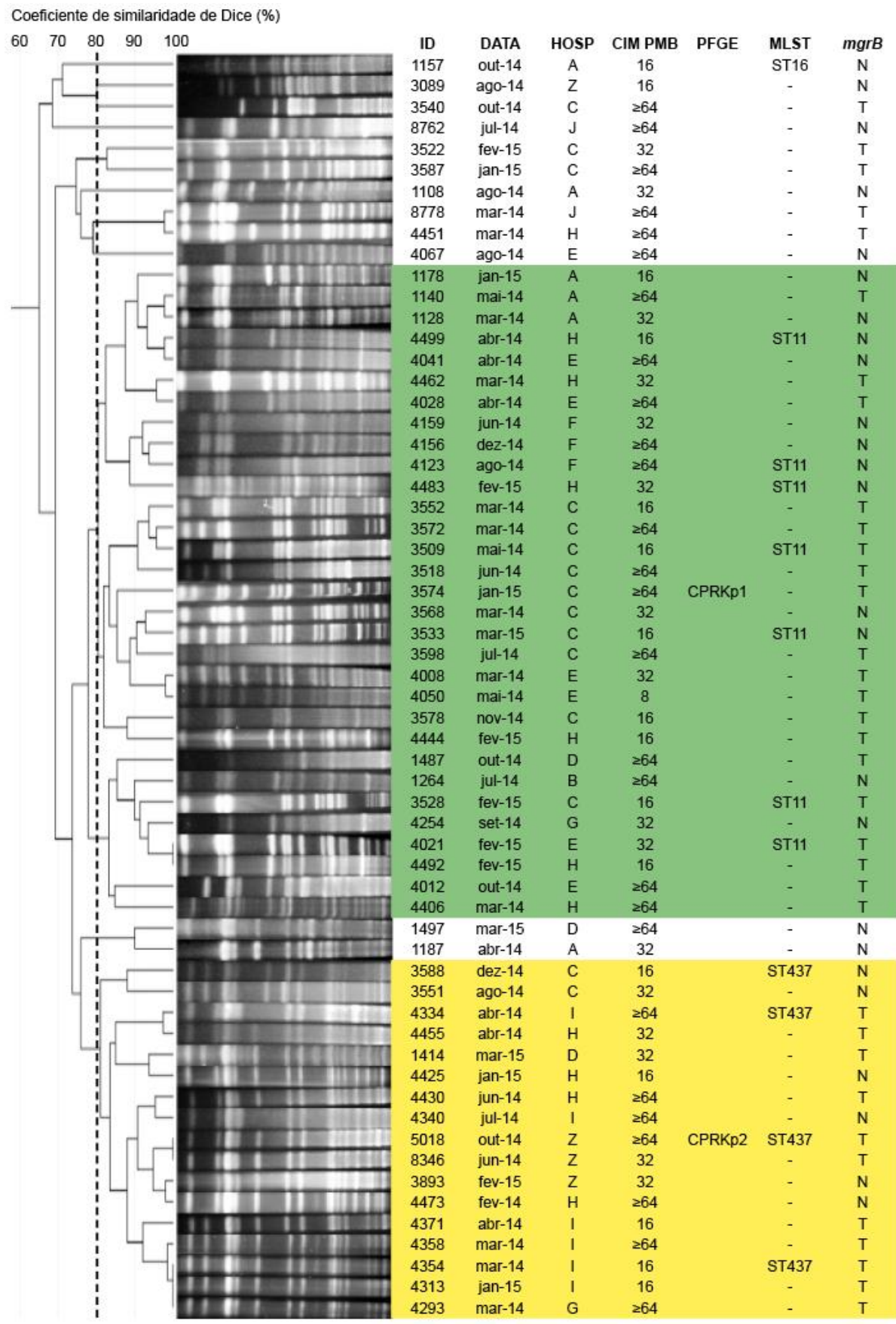

Figura 9. Diversidade clonal e integridade do gene $\mathrm{mgrB}$ entre isolados de Klebsiella pneumoniae resistentes a carbapenêmicos e polimixina $B$ obtidos de pacientes hospitalizados na Grande São Paulo (2014 e 2015). ID: identificação do isolado; HOSP: hospital; CIM PMB: concentração inibitória mínima de polimixina B (mg/L); PFGE: grupo clonal obtido por eletroforese em campo pulsado; os isolados destacados em verde e amarelo representam os dois maiores grupos clonais CPRKp1 e CPRKp2, respectivamente; MLST: tipagem por sequenciamento de múltiplos genes; $\operatorname{mgrB}$ : integridade do gene $\operatorname{mgr} B$ de acordo com o tamanho do produto da PCR, onde "T" simboliza o gene truncado, cujo o fragmento apresentou tamanho superior à $250 \mathrm{pb}$ (pares de bases), e "N" simboliza o gene de tamanho equivalente ao controle de $250 \mathrm{pb}$. Todos os isolados foram negativos para o gene $\mathrm{mcr}$ - 1 . Uma versão ampliada desta figura encontra-se na Apêndice B. 


\subsection{Análise do mecanismo de resistência à polimixina $B$}

Pesquisou-se, entre os mesmos 60 isolados citados acima, a ocorrência de inserções no gene $\operatorname{mgr} B$. Na visualização da eletroforese em gel dos fragmentos de DNA resultantes da amplificação do gene por PCR (Figura 10), foi possível distinguir fragmentos de aproximadamente 250 pares de bases (pb), correspondendo ao produto de amplificação incluindo o gene $m g r B$ íntegro, e também de fragmentos maiores, cujo tamanho variou de aproximadamente 700 a $1300 \mathrm{pb}$. Os fragmentos maiores foram considerados como o gene $m g r B$ truncado com sequências de inserção, tal como descrito previamente.

Alguns produtos com tamanho maior que $250 \mathrm{pb}$ foram sequenciados e comparados utilizando-se o BLAST. Foi evidenciada a presença de sequências de inserção truncando o gene $\operatorname{mgr} B$. Foram detectadas sequências de inserção com pelo menos $99 \%$ de similaridade: IS1A (768 bps) nos isolados 3518 e 3572; ISAs22 (1198 pbs) no isolado 4021; ISKpn26 (1196 pbs) no isolado 4334; IS1R (768 pbs) nos isolados 4430 e 5018.

A PCR para o gene $m c r-1$ foi negativa em todos os 60 isolados analisados neste estudo.

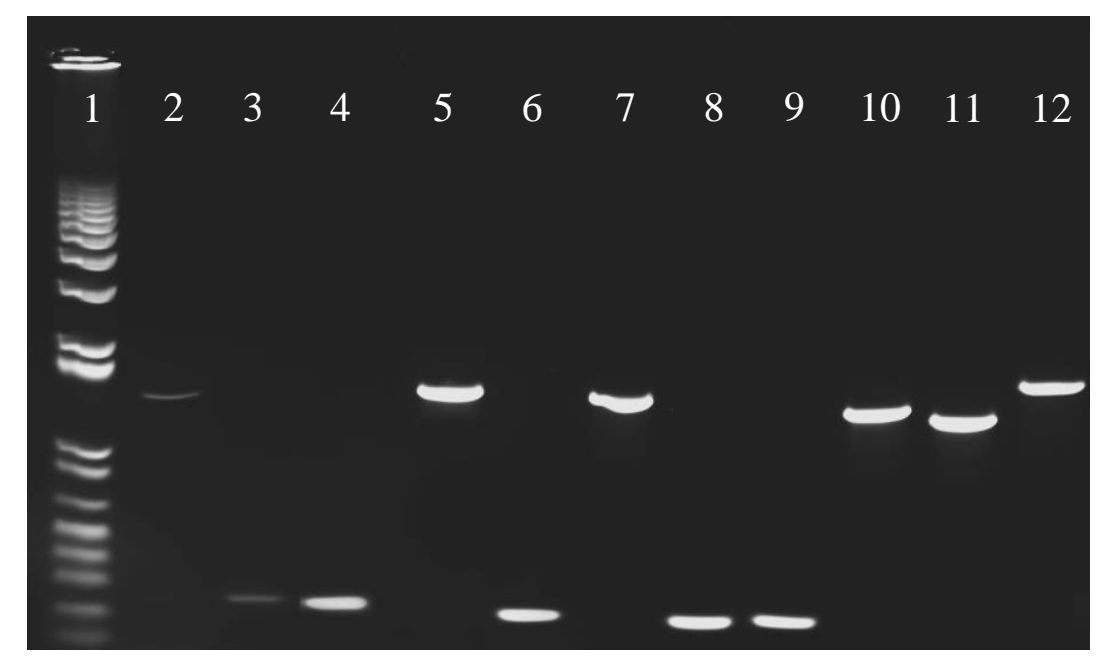

Figura 10. Foto de gel obtido através da eletroforese de fragmentos de DNA após a PCR para amplificação do gene $\boldsymbol{m g r B}$ para exemplificação. A canaleta 1 contém o padrão molecular $1 \mathrm{kbPlus}^{\circledR}$ (Invitrogen ${ }^{\circledR}$ ), enquanto as canaletas 2 e 3 apresentam os controles do gene truncado e íntegro, respectivamente. Nas demais canaletas observam-se os produtos da amplificação por PCR do gene $m g r B$ de isolados de Klebsiella pneumoniae resistentes à polimixina B. 


\section{DISCUSSÃO}

Observou-se, através deste estudo, um crescimento alarmante da resistência à polimixina B entre isolados de CRKp obtidos de pacientes hospitalizados da Grande São Paulo durante os últimos cinco anos. Este é o dado mais recente e mais abrangente acerca da resistência à polimixinas por Enterobacteriaceae na região que atualmente é considerada a oitava maior aglomeração humana do planeta. Os altos níveis de resistência ocorreram principalmente em isolados resistentes à carbapenêmicos $(27,1 \%$ em 2015), produtores de KPC, assemelhando-se aos níveis descritos anteriormente em outras regiões do mundo (AH; KIM; LEE, 2014). Essa característica mostra uma possível relação com o aumento do uso de polimixinas como alternativa terapêutica aos carbapenêmicos no tratamento de infeções provocadas por KPC-Kp, fato de grande preocupação, uma vez que isolados de $K$. pneumoniae produtores de KPC-2 são endêmicos em grande parte das instituições de saúde do Brasil (ANDRADE et al., 2011). Entretanto, as taxas de resistência observadas neste estudo podem ser inferiores às taxas reais, uma vez que foram excluídos os exames repetidos de um mesmo paciente quando realizados em um intervalo menor que 90 dias. Nessas condições, e sem a revisão dos prontuários dos pacientes, não foi possível avaliar a incidência de heterorresistência ou a ocorrência de resistência durante o tratamento com polimixina B. Apesar dessa limitação, o estudo evidenciou taxas alarmantes de resistência às polimixinas nos isolados resistentes aos carbapenêmicos, contexto no qual as polimixinas são amplamente utilizadas empiricamente.

A distribuição bimodal das CIMs de polimixina B mostrou dois grupos principais cujo ponto de separação das curvas era compatível com o ponto de corte estabelecido pelo EUCAST para colistina. Assim, este trabalho evidenciou que é possível utilizar o mesmo ponto de corte para colistina em ensaios de microdiluição com polimixina B. Também foi evidenciado que isolados de CPRKp apresentam em sua maioria altos níveis de resistência à polimixina $\mathrm{B}$ ( $\geq 16 \mathrm{mg} / \mathrm{L})$, os quais são uma problemática no tratamento dessas infecções multirresistentes. Uma vez que o perfil de PK/PD das polimixinas é baseado na razão AUC/CIM, são necessárias doses mais elevadas quanto maior a CIM do microoganismo, aumentando o risco de eventos adversos, principalmente relacionados à nefrotoxicidade, atuando como um fator limitante no uso das polimixinas. Assim, a terapia combinada de antimicrobianos é recomendada em casos de infecções multirresistentes. Na análise da susceptibilidade aos antimicrobianos alternativos realizada neste trabalho, nenhum antimicrobiano apresentou sensibilidade superior a $80 \%$ entre os isolados CRKp e CPRKp, 
fato que desencoraja ainda mais a monoterapia no manejo empírico dessas infecções. A amicacina e a tigeciclina foram os antimicrobianos com maior taxa de sensibilidade, ao passo que fosfomicina, cloranfenicol e gentamicina não apresentaram sensibilidade satisfatória para o tratamento empírico de infecções por K. pneumoniae multirresistente.

Entre os 60 isolados analisados neste trabalho, foi encontrada a predominância de dois grupos clonais entre CPRKp: ST11 e ST437, ambos pertencentes ao complexo clonal 258, apresentando disseminação intra e interhospitalar. Anteriormente a predominância do complexo clonal 258 já havia sido relatada entre $K$. pneumoniae produtora de KPC-2 no Brasil, porém não em CPRKp (ANDRADE et al., 2011; SEKI et al., 2011). Esse achado sugere determinantes ocorrência de eventos genéticos que conferiram a resistência à polimixina B. A disseminação de isolados ST11 foi reportada com maior frequência em países asiáticos (CHENG et al., 2016), ao passo que isolados ST437 foram encontrados na China e Espanha (SEARA et al., 2015; SHEN et al., 2016), porém não havia relatos de isolados de CPRKp para esse grupo clonal. Surtos de CPRKp foram reportados em hospitais na Europa e nos Estados Unidos (ANTONIADOU et al., 2007; GIANI et al., 2015a; MARCHAIM et al., 2011; MEZZATESTA et al., 2011), entretanto poucos estudos (WETERINGS et al., 2015) relataram disseminação interhospitalar, tal como descrita neste trabalho. Esse achado é alarmante na medida em que evidencia a disseminação de clones com alto nível de resistência não somente intrahospitalar, mas também entre hospitais, públicos e privados. A disseminação de clones evidencia transmissão cruzada, forma cuja prevenção tem sido o principal foco das comissões de controle de infecções em ambientes hospitalares. Nossos achados evidenciam a necessidade de implementação de medidas de controle mais rigorosas na adesão às medidas de precauções de contato, uma vez que todas as instituições envolvidas no estudo tem rotina de avaliação de colonização do trato digestório por enterobactérias resistentes aos carbapenêmicos e implementam medidas de precauções de contato sempre que há colonização ou infecção. Vários autores tem demonstrado que a colonização precede e é uma fator de risco para a ocorrência de infecção por Klebsiella pneumoniae resistente aos carbapenêmicos e polimixinas (MACHUCA et al., 2016).

Em relação aos mecanismos de resistência à polimixina, não foi detectado, em nenhum dos isolados de CRPKp analisados neste estudo, o gene mcr-1, apesar de anteriormente já ter sido relatado sua presença em K. pneumoniae (DI PILATO et al., 2016; ROLAIN et al., 2016). Esse fato pode ser devido ao número limitado de isolados analisados (60) neste estudo, frente à baixa prevalência observada em isolados de origem humana, diferentes estudos. No Brasil, até o momento, há relatos da presença do gene apenas em $E$. 
coli (FERNANDES et al., 2016; FERNANDES et al., 2016; LENTZ et al., 2016).

Entretanto, em 35 dos 60 isolados de CPRKp foi possível identificar o gene $\operatorname{mgr} B$ truncado, revelando ser o mecanismo de resistência mais comum entre esses isolados. Os demais 25 isolados que apresentaram integridade do gene provavelmente possuem outros mecanismos de resistência, tais como mutações nos genes que codificam o sistema de transdução de sinal PmrA/PmrB (JAYOL et al., 2014) ou da produção da cápsula polissacarídica (CAMPOS et al., 2004). Também é possível estimar que esses isolados apresentem mutação no próprio gene $\operatorname{mgrB}$ ou algum mecanismo de resistência adaptativa, os quais também não foram pesquisados neste trabalho. Essas dúvidas, cujas limitações deste estudo deixaram em aberto, servem, no entanto, de mote para futuros projetos envolvendo a resistência às polimixinas neste país, uma vez que o truncamento do gene $\operatorname{mgrB}$ por sequencias de inserção pode ocorrer durante o tratamento com polimixinas (CANNATELLI et al., 2013), fato que também gera preocupação e acende o alarme para que medidas de controle e uso racional das polimixinas, tanto em hospitais como na pecuária e avicultura, sejam implementadas.

Em suma, através do presente estudo foi possível evidenciar a ascensão alarmante da resistência à polimixina $\mathrm{B}$ entre isolados de CRKP, com disseminação intra e interhospitalar de CPRKP pertencentes ao complexo clonal 258 em hospitais públicos e privados da cidade de São Paulo. Esses achados são preocupantes no que toca à atenção sanitária, uma vez que esses isolados pan-resistentes tem alto potencial de ameaçar a efetividade do atual arsenal da terapia antimicrobiana, cujo cenário para um futuro próximo poderá ser uma epidemia de infecções incuráveis no país. 


\section{CONCLUSÕES}

Houve aumento significativo da resistência aos carbapenêmicos por $K$. pneumoniae entre pacientes hospitalizados na Grande São Paulo no período de 2011 a 2015. O mesmo foi observado para a polimixina B, sendo o aumento mais expressivo entre CRKp.

A maior parte dos isolados resistentes aos carbapenêmicos e à polimixina B apresentaram altos níveis de CIM para polimixina B.

Tigeciclina e amicacina foram os antibimicrobianos que apresentaram maior taxa de sensibilidade entre isolados resistente aos carbapenêmicos e à polimixina B.

A predominância de dois grupos clonais: ST11 e ST437, ambos pertencentes ao complexo clonal 258, evidencia a disseminação intra e interhospitalar de clones de CPRKp.

O mecanismo de resistência mais comum entre os isolados de CPRKp foi a presença de sequências de inserção truncando o gene $\operatorname{mgrB}$.

Não foi detectado o gene $m c r-1$ em nenhum dos isolados estudados 


\section{REFERÊNCIAS}

ABDELRAOUF, K. et al. Characterization of polymyxin B-induced nephrotoxicity: Implications for dosing regimen design. Antimicrobial Agents and Chemotherapy, v. 56, n. 9, p. 4625-4629, 2012.

AH, Y. M.; KIM, A. J.; LEE, J. Y. Colistin resistance in Klebsiella pneumoniae. International Journal of Antimicrobial Agents, 2014.

AKAJAGBOR, D. S. et al. Higher incidence of acute kidney injury with intravenous colistimethate sodium compared with polymyxin B in critically ill patients at a tertiary care medical center. Clinical infectious diseases: an official publication of the Infectious Diseases Society of America, v. 57, n. 9, p. 1300-3, 2013.

ANDRADE, L. N. et al. Dissemination of blaKPC-2by the spread of Klebsiella pneumoniae clonal complex 258 clones (ST258, ST11, ST437) and plasmids (IncFII, IncN, IncL/M) among Enterobacteriaceae species in Brazil. Antimicrobial Agents and Chemotherapy, v. 55 , n. 7, p. 3579-3583, 2011.

ANTONIADOU, A. et al. Colistin-resistant isolates of Klebsiella pneumoniae emerging in intensive care unit patients: First report of a multiclonal cluster. Journal of Antimicrobial Chemotherapy, v. 59, n. 4, p. 786-790, 2007.

ANVISA. Nota técnica 01/2013: Medidas de prevenção e controle de infecções por enterobactérias multirresistentes. Disponível em: http://portal.anvisa.gov.br/wps/wcm/connect/ea4d4c004f4ec3b98925d9d785749fbd/Microsoft +Word+-

+NOTA+TÉCNICA+ENTEROBACTERIAS+17+04+2013(1).pdf?MOD=AJPERES>.

Acesso em: 12 fev. 2014

ARENA, F. et al. Colistin Resistance Caused by Inactivation of the MgrB Regulator Is Not Associated with Decreased Virulence of Sequence Type 258 KPC Carbapenemase-Producing Klebsiella pneumoniae. Antimicrobial Agents and Chemotherapy , v. 60 , n. 4 , p. 25092512, 1 abr. 2016.

ARNOLD, T. M.; FORREST, G. N.; MESSMER, K. J. Polymyxin antibiotics for gramnegative infectionsAmerican Journal of Health-System Pharmacy, 2007.

BARIN, J. et al. Hetero- and adaptive resistance to polymyxin B in OXA-23-producing carbapenem-resistant Acinetobacter baumannii isolates. Annals of clinical microbiology and antimicrobials, v. 12, n. 1, p. 15, 2013.

BISWAS, S. et al. Colistin: an update on the antibiotic of the 21st century. Expert Review of Anti-infective Therapy, v. 10, n. 8, p. 917-934, 2012.

BOGDANOVICH, T. et al. Colistin-resistant, Klebsiella pneumoniae Carbapenemase (KPC)producing Klebsiella pneumoniae belonging to the international epidemic clone ST258. Clinical Infectious Diseases, v. 53, n. 4, p. 373-376, 2011.

BOUCHER, H. W. et al. Bad bugs, no drugs: no ESKAPE! An update from the Infectious Diseases Society of America. Clinical infectious diseases : an official publication of the Infectious Diseases Society of America, v. 48, n. 1, p. 1-12, 2009.

CAMPOS, M. A. et al. Capsule polysaccharide mediates bacterial resistance to antimicrobial peptides. Infection and Immunity, v. 72, n. 12, p. 7107-7114, 2004.

CANNATELLI, A. et al. In vivo emergence of colistin resistance in Klebsiella pneumoniae 
producing KPC-type carbapenemases mediated by insertional inactivation of the $\mathrm{PhoQ} / \mathrm{PhoP}$ mgrB regulator. Antimicrobial Agents and Chemotherapy, v. 57, n. 11, p. 5521-5526, 2013.

CAPONE, A. et al. High rate of colistin resistance among patients with carbapenem-resistant Klebsiella pneumoniae infection accounts for an excess of mortality. Clinical Microbiology and Infection, v. 19, n. 1, 2013.

CATRY, B. et al. Use of colistin-containing products within the European Union and European Economic Area (EU/EEA): development of resistance in animals and possible impact on human and animal health. International Journal of Antimicrobial Agents, v. 46, n. 3, p. 297-306, 2015.

CAVASSIN, E. D.; TOSHIE, E.; SANTOS, C. C.; SAMPAIO, S. C. F.; SAMPAIO, J. L. M. Discrepancies in susceptibility testing of KPC producing Klebsiella pneumoniae using Vitek2. In: Abstracts of the 21st ECCMID / 27th ICC, Milan, Italy, 2011.

CHEN, H. D.; GROISMAN, E. A. The biology of the PmrA/PmrB two-component system: the major regulator of lipopolysaccharide modifications. Annual Review of Microbiology, v. 67 , n. 1, p. 83-112, 2013.

CHEN, S. et al. Independent emergence of colistin-resistant Enterobacteriaceae clinical isolates without colistin treatmentJournal of Clinical Microbiology, 2011.

CHENG, L. et al. Clonal dissemination of KPC-2 producing Klebsiella pneumoniae ST11 clone with high prevalence of oqx $\mathrm{AB}$ and $\mathrm{rmtB}$ in a tertiary hospital in China: results from a 3-year period. Annals of Clinical Microbiology and Antimicrobials, v. 15, n. 1, p. 1-8, 2016.

CHOPRA, I.; HESSE, L.; O’NEILL, A. J. Exploiting current understanding of antibiotic action for discovery of new drugs. Journal of Applied Microbiology, v. 92 Suppl, p. 4S$15 \mathrm{~S}, 2002$.

CLSI. Performance Standards for Antimicrobial Susceptibility Testing; Twenty-Fifth Informational Supplement. [s.l: s.n.].

COSGROVE, S. E. The relationship between antimicrobial resistance and patient outcomes: mortality, length of hospital stay, and health care costs. Clinical infectious diseases : an official publication of the Infectious Diseases Society of America, v. 42 Suppl 2, n. Suppl 2, p. S82-S89, 2006.

COUET, W. et al. Pharmacokinetics of colistin and colistimethate sodium after a single 80$\mathrm{mg}$ intravenous dose of CMS in young healthy volunteers. Clinical pharmacology and therapeutics, v. 89, n. 6, p. 875-879, 2011.

DE OLIVEIRA, M. S. et al. Treatment of KPC-producing Enterobacteriaceae: Suboptimal efficacy of polymyxins. Clinical Microbiology and Infection, v. 21, n. 2, p. 179.e1-179.e7, 2015.

DE ROSA, F. G. et al. Critical issues for Klebsiella pneumoniae KPC-carbapenemase producing K. pneumoniae infections: a critical agenda. Future Microbiology, v. 10, n. 2, p. 283-294, 2015.

DHAR, S. et al. Risk Factors and Outcomes for Carbapenem-Resistant Klebsiella pneumoniae Isolation, Stratified by Its Multilocus Sequence Typing: ST258 Versus Non-ST258. Open forum infectious diseases, v. 3, n. 1, p. ofv213, 2016.

DI PILATO, V. et al. mcr-1.2, a New mor Variant Carried on a Transferable Plasmid from a 
Colistin-Resistant KPC Carbapenemase-Producing Klebsiella pneumoniae Strain of Sequence Type 512. Antimicrobial Agents and Chemotherapy , v. 60 , n. 9 , p. 5612-5615, 1 set. 2016.

DIANCOURT, L. et al. Multilocus sequence typing of Klebsiella pneumoniae nosocomial isolates. Journal of Clinical Microbiology, v. 43, n. 8, p. 4178-4182, 2005.

DIJKMANS, A. C. et al. Colistin: revival of an old polymyxin antibiotic. Therapeutic drug monitoring, v. 37, n. 4, p. 419-427, 2014.

DUBROVSKAYA, Y. et al. Risk factors for treatment failure of polymyxin B monotherapy for carbapenem-resistant Klebsiella pneumoniae infections. Antimicrobial agents and chemotherapy, v. 57, n. 11, p. 5394-7, 2013.

DUBROVSKAYA, Y. et al. 05_05 Risk factors for nephrotoxicity onset associated with polymyxin B therapy. Journal of Antimicrobial Chemotherapy, n. February, p. 1903-1907, 2015.

EUCAST. EUCAST. Disponível em: <http://www.eucast.org/ast_of_bacteria/> .

EUCAST. Recommendations for MIC determination of colistin (polymyxin E) As recommended by the joint CLSI-EUCAST Polymyxin Breakpoints Working Group. [s.l: s.n.].

$<$ http://www.eucast.org/fileadmin/src/media/PDFs/EUCAST_files/General_documents/Reco mmendations_for_MIC_determination_of_colistin_March_2016.pdf $>$.

FALAGAS, M. E.; KASIAKOU, S. K.; SARAVOLATZ, L. D. Colistin: The Revival of Polymyxins for the Management of Multidrug-Resistant Gram-Negative Bacterial Infections. Clinical Infectious Diseases, v. 40, n. 9, p. 1333-1341, 2005.

FALAGAS, M. E.; RAFAILIDIS, P. I.; MATTHAIOU, D. K. Resistance to polymyxins: Mechanisms, frequency and treatment options. Drug Resistance Updates, v. 13, n. 4-5, p. 132-138, 2010.

FERNANDES, M. R. et al. First Report of the Globally Disseminated IncX4 Plasmid Carrying the mcr-1 Gene in a Colistin-Resistant Escherichia coli ST101 isolated from a Human Infection in Brazil. Antimicrobial Agents and Chemotherapy , 8 ago. 2016.

GALES, A. C.; JONES, R. N.; SADER, H. S. Global assessment of the antimicrobial activity of polymyxin B against 54731 clinical isolates of Gram-negative bacilli: Report from the SENTRY antimicrobial surveillance programme (2001-2004). Clinical Microbiology and Infection, v. 12, n. 4, p. 315-321, 2006.

GALES, A. C.; JONES, R. N.; SADER, H. S. Contemporary activity of colistin and polymyxin B against a worldwide collection of Gram-negative pathogens: Results from the SENTRY antimicrobial surveillance program (2006-09). Journal of Antimicrobial Chemotherapy, v. 66, n. 9, p. 2070-2074, 2011.

GARZA-RAMOS, U. et al. Characteristics of KPC-2-producing Klebsiella pneumoniae (ST258) clinical isolates from outbreaks in 2 Mexican medical centers. Diagnostic Microbiology and Infectious Disease, v. 79, n. 4, p. 483-485, ago. 2014.

GIACOBBE, D. R. et al. Risk factors for bloodstream infections due to colistin-resistant KPC-producing Klebsiella pneumoniae: Results from a multicenter case-control-control study. Clinical Microbiology and Infection, 2015.

GIAMARELLOU, H.; POULAKOU, G. Multidrug-resistant gram-negative infections: What are the treatment options?Drugs, 2009. 
GIANI, T. et al. Large nosocomial outbreak of colistin-resistant, carbapenemase-producing klebsiella pneumoniae traced to clonal expansion of an mgrb deletion mutant. Journal of Clinical Microbiology, v. 53, n. 10, p. 3341-3344, 2015a.

GIANI, T. et al. Large Nosocomial Outbreak of Colistin-Resistant, CarbapenemaseProducing Klebsiella pneumoniae Traced to Clonal Expansion of an mgrB Deletion Mutant. Journal of clinical microbiology, v. 53, n. 10, p. 3341-4, 1 out. 2015 b.

GLASNER, C. et al. Carbapenemase-producing Enterobacteriaceae in Europe: A survey among national experts from 39 countries, February 2013. Eurosurveillance, v. 18, n. 28, 2013.

GOMEZ-SIMMONDS, A. et al. Population Structure of Klebsiella pneumoniae Causing Bloodstream Infections at a New York City Tertiary Care Hospital: Diversification of Multidrug-Resistant Isolates. Journal of Clinical Microbiology, v. 53, n. 7, p. 2060-2067, 15 jul. 2015.

HELANDER, I. M. et al. Characterization of lipopolysaccharides of polymyxin-resistant and polymyxin-sensitive Klebsiella pneumoniae O3. European journal of biochemistry / FEBS, v. 237, p. 272-278, 1996.

HERAS, J. et al. GelJ -- a tool for analyzing DNA fingerprint gel images. BMC Bioinformatics, v. 16, n. 1, p. 1-8, 2015.

HIRSCH, E. B.; TAM, V. H. Detection and treatment options for Klebsiella pneumoniae carbapenemases (KPCs): An emerging cause of multidrug-resistant infection. Journal of Antimicrobial Chemotherapy, v. 65, n. 6, p. 1119-1125, 2010.

IRRGANG, A. et al. Prevalence of mcr-1 in E. coli from Livestock and Food in Germany, 2010-2015. PloS one, v. 11, n. 7, p. e0159863, 25 jan. 2016.

JAYOL, A. et al. Resistance to Colistin Associated with a Single Amino Acid Change in Protein PmrB among Klebsiella pneumoniae Isolates of Worldwide Origin. Antimicrobial Agents and Chemotherapy, v. 58, n. 8, p. 4762-4766, 13 ago. 2014.

JIAO, Y. et al. Risk factors for carbapenem-resistant Klebsiella pneumoniae infection/colonization and predictors of mortality: a retrospective study. Pathogens and global health, v. 109, n. 2, p. 68-74, 2015.

JONES, R. N.; ANDEREGG, T. R.; SWENSON, J. M. Quality control guidelines for testing gram-negative control strains with polymyxin B and colistin (polymyxin E) by standardized methods. Journal of Clinical Microbiology, v. 43, n. 2, p. 925-927, 2005.

JUSTO, J. A.; BOSSO, J. A. Adverse reactions associated with systemic polymyxin therapy. Pharmacotherapy, v. 35, n. 1, p. 28-33, 2015.

KANJ, S. S.; KANAFANI, Z. A. Current concepts in antimicrobial therapy against resistant gram-negative organisms: extended-spectrum beta-lactamase-producing Enterobacteriaceae, carbapenem-resistant Enterobacteriaceae, and multidrug-resistant Pseudomonas aeruginosa. Mayo Clinic proceedings, v. 86, n. 3, p. 250-9, 2011.

KARAISKOS, I. et al. Colistin Population Pharmacokinetics after Application of a Loading Dose of 9 MU Colistin Methanesulfonate in Critically Ill Patients. Antimicrobial Agents and Chemotherapy, v. 59, n. 12, p. 7240-7248, 14 dez. 2015.

KASSAMALI, Z.; DANZIGER, L. To B or not to B, that is the question: Is it time to replace colistin with polymyxin B? Pharmacotherapy, v. 35, n. 1, p. 17-21, 2015.

KOCH-WESER, J. A. N. et al. Adverse Effects of Sodium ColistimethateManifestations and 
Specific Reaction Rates During 317 Courses of Therapy. Annals of Internal Medicine, v. 72, n. 6, p. 857-868, 1 jun. 1970.

KUBIN, C. J. et al. Incidence and predictors of acute kidney injury associated with intravenous polymyxin B therapy. The Journal of infection, v. 65, n. 1, p. 80-7, 2012.

LANDMAN, D. et al. Polymyxins revisitedClinical Microbiology Reviews, 2008.

LEE, G. C.; BURGESS, D. S. Treatment of Klebsiella pneumoniae carbapenemase (KPC) infections: a review of published case series and case reports. Annals of clinical microbiology and antimicrobials, v. 11, p. 32, 2012.

LEVY HARA, G. et al. Detection, treatment, and prevention of carbapenemase-producing Enterobacteriaceae: recommendations from an International Working Group. Journal of chemotherapy (Florence, Italy), v. 25, n. 3, p. 129-40, 2013.

LI, J. et al. Heteroresistance to colistin in multidrug-resistant Acinetobacter baumannii. Antimicrobial Agents and Chemotherapy, v. 50, n. 9, p. 2946-2950, 2006.

LIU, Y. Y. et al. Emergence of plasmid-mediated colistin resistance mechanism MCR-1 in animals and human beings in China: A microbiological and molecular biological study. The Lancet Infectious Diseases, 2015.

LLOBET, E. et al. Analysis of the networks controlling the antimicrobial-peptide-dependent induction of Klebsiella pneumoniae virulence factors. Infection and Immunity, v. 79, n. 9, p. 3718-3732, 2011.

LOMBARDI, F. et al. Emergence of Carbapenem-Resistant Klebsiella pneumoniae: Progressive Spread and Four-Year Period of Observation in a Cardiac Surgery Division. BioMed Research International, v. 2015, p. 871947, 4 maio 2015.

MACHUCA, I. et al. Oral decontamination with aminoglycosides is associated with lower risk of mortality and infections in high-risk patients colonized with colistin-resistant, KPCproducing Klebsiella pneumoniae. Journal of Antimicrobial Chemotherapy , 26 jul. 2016.

MARCHAIM, D. et al. Outbreak of colistin-resistant, carbapenem-resistant Klebsiella pneumoniae in Metropolitan Detroit, Michigan. Antimicrobial Agents and Chemotherapy, v. 55, n. 2, p. 593-599, 2011.

MAVROIDI, A. et al. Characterization of ST258 Colistin-Resistant, blaKPC-Producing Klebsiella pneumoniae in a Greek Hospital. Microbial Drug Resistance, v. 22, n. 5, p. 392398, 3 fev. 2016.

MELETIS, G. et al. Colistin heteroresistance in carbapenemase-producing Klebsiella pneumoniae. The Journal of antimicrobial chemotherapy, v. 66, n. 4, p. 946-7, 1 abr. 2011.

MEZZATESTA, M. L. et al. Outbreak of KPC-3-producing, and colistin-resistant, Klebsiella pneumoniae infections in two Sicilian hospitals. Clinical Microbiology and Infection, v. 17, n. 9, p. 1444-1447, 2011.

MONACO, M. et al. Colistin resistance superimposed to endemic carbapenem-resistant Klebsiella pneumoniae: a rapidly evolving problem in Italy, November 2013 to April 2014. Euro surveillance: bulletin Europ??en sur les maladies transmissibles = European communicable disease bulletin, v. 19, n. 42, 2014.

MOSKOWITZ, S. M. et al. PmrB mutations promote polymyxin resistance of Pseudomonas aeruginosa isolated from colistin-treated cystic fibrosis patients. Antimicrobial Agents and Chemotherapy, v. 56, n. 2, p. 1019-1030, 2012. 
MR FERNANDES, Q MOURA, L SARTORI, KC SILVA, MP CUNHA, F ESPOSITO, R LOPES, LK OTUTUMI, DD GONÇALVES, M DROPA, MH MATTÉ, DF MONTE, M LANDGRAF, GR FRANCISCO, MF BUENO, D DE OLIVEIRA GARCIA, T KNÖBL, AM MORENO, N. L. Silent dissemination of colistin-resistant Escherichia coli in South America could contribute to the global spread of the mcr-1 gene. Eurosurveillance, v. 21, n. 17, 2016.

NATION, R. L. et al. Framework for optimisation of the clinical use of colistin and polymyxin B: The Prato polymyxin consensusThe Lancet Infectious Diseases, 2015.

NOBELPRIZE.ORG.The Official Web Site Of The Nobel Prize. Sir Alexander Fleming Biography. [S.1.] Disponível em:

<http://www.nobelprize.org/nobel_prizes/medicine/laureates/1945/fleming-bio.html>. Acesso em: 05 mar. 2012

NORDMANN, P.; CUZON, G.; NAAS, T. The real threat of Klebsiella pneumoniae carbapenemase-producing bacteriaThe Lancet Infectious Diseases, 2009.

ORTWINE, J. K. et al. Colistin: Understanding and applying recent Pharmacokinetic advancesPharmacotherapy, 2015.

PEREIRA, G. H. et al. Spread of carbapenem-resistant Klebsiella pneumoniae in a tertiary hospital in Sao Paulo, Brazil. Journal of Hospital Infection, v. 79, n. 2, p. 182-183, 2 mar. 2011.

PHE, K. et al. In vitro assessment and multicenter cohort study of comparative nephrotoxicity rates associated with colistimethate versus polymyxin b therapy. Antimicrobial Agents and Chemotherapy, v. 58, n. 5, p. 2740-2746, 2014.

POIREL, L. et al. The mgrB gene as a key target for acquired resistance to colistin in Klebsiella pneumoniae. Journal of Antimicrobial Chemotherapy, v. 70, n. 1, p. 75-80, 2015.

QUEENAN, A. M.; BUSH, K. Carbapenemases: The versatile ??-lactamasesClinical Microbiology Reviews, 2007.

RIBEIRO, V. B. et al. Detection of bla $\mathrm{KPC}_{-2}$ in a carbapenem-resistant Kluyvera georgiana. Journal of Antimicrobial Chemotherapy, v. 67, p. 2776-2777, 2012.

RIBOT, E. M. et al. Standardization of pulsed-field gel electrophoresis protocols for the subtyping of Escherichia coli O157:H7, Salmonella, and Shigella for PulseNet. Foodborne pathogens and disease, v. 3, n. 1, p. 59-67, 2006.

RIGATTO, M. H. et al. Renal failure in patients treated with colistin versus polymyxin B: a multicenter prospective cohort study. Antimicrobial Agents and Chemotherapy, v. 60, n. 4, p. AAC.02634-15, 2016.

ROLAIN, J.-M. et al. Plasmid-mediated mcr-1 gene in colistin-resistant clinical isolates of Klebsiella pneumoniae in France and Laos. Antimicrobial Agents and Chemotherapy , 29 ago. 2016.

SA LENTZ, D DE LIMA-MORALES, VM CUPPERTINO, LDS NUNES, AS DA MOTTA, AP ZAVASCKI, A. B.; AF MARTINS. Letter to the editor: Escherichia coli harbouring mcr1 gene isolated from poultry not exposed to polymyxins in Brazil. Eurosurveillance, v. 21, n. 26, 2016.

SADER, H. S. et al. Antimicrobial susceptibility of Gram-negative organisms isolated from patients hospitalised with pneumonia in US and European hospitals: Results from the SENTRY Antimicrobial Surveillance Program, 2009-2012. International Journal of 
Antimicrobial Agents, v. 43, n. 4, p. 328-334, 2014.

SEARA, N. et al. Interhospital spread of NDM-7-producing Klebsiella pneumoniae belonging to ST437 in Spain. International Journal of Antimicrobial Agents, v. 46, n. 2, p. 169-173, 2015.

SEKI, L. M. et al. Molecular epidemiology of KPC-2- producing Klebsiella pneumoniae isolates in Brazil: The predominance of sequence type 437. Diagnostic Microbiology and Infectious Disease, v. 70, n. 2, p. 274-277, 2011.

SHEN, P. et al. Characterization of the genetic environment of the blaKPC-2 gene among Klebsiella pneumoniae isolates from a Chinese Hospital. The Brazilian Journal of Infectious Diseases, v. 20, n. 4, p. 384-388, jul. 2016.

TAVARES, W. Antibióticos e Quimioterápicos para o Clínico. $3^{\mathrm{a}}$ edição. São Paulo: Atheneu, 2014.

TENOVER, F. et al. Interpreting chromosomal DNA restriction patterns produced by pulsedfield gel electrophoresis: criteria for bacterial strain typing. J. Clin. Microbiol., v. 33, n. 9, p. 2233-2239, 1 set. 1995.

TÓTH, Á. et al. Emergence of a colistin-resistant KPC-2-producing Klebsiella pneumoniae ST258 clone in Hungary. European Journal of Clinical Microbiology \& Infectious Diseases, v. 29, n. 7, p. 765-769, 2010.

TSAKRIS, A. et al. Evaluation of boronic acid disk tests for differentiating KPC-possessing Klebsiella pneumoniae isolates in the clinical laboratory. Journal of Clinical Microbiology, v. 47, n. 2, p. 362-367, 2009.

TUON, F. F. et al. Risk factors for acute kidney injury in patients treated with polymyxin B or colistin methanesulfonate sodium. International Journal of Antimicrobial Agents, v. 43, n. 4, p. 349-352, 2014.

UPTODATE. In: UpToDate, Post TW (Ed), UpToDate, Waltham, MA. Disponível em: $<$ http://www.uptodate.com/contents/polymyxin-b-drug-

information?source=search_result\&search=polymyxin+B\&selectedTitle $=1 \sim 84>$. Acesso em 15 fev. 2015.

VAN DUIN, D. et al. Carbapenem-resistant Enterobacteriaceae: A review of treatment and outcomesDiagnostic Microbiology and Infectious Disease, 2013.

VAN DUIN, D.; DOI, Y. Outbreak of colistin-resistant, carbapenemase-producing klebsiella pneumoniae: Are we at the end of the road?Journal of Clinical Microbiology, 2015.

VATTIMO, M. DE F. F. et al. Polymyxin B Nephrotoxicity: From Organ to Cell Damage. PLoS ONE, v. 11, n. 8, p. e0161057, 17 ago. 2016.

VELKOV, T. et al. Pharmacology of polymyxins: new insights into an "old" class of antibiotics. Future Microbiol, v. 8, n. 6, p. 1-20, 2013.

WETERINGS, V. et al. An outbreak of colistin-resistant Klebsiella pneumoniae carbapenemase-producing Klebsiella pneumoniae in the Netherlands (July to December 2013), with inter-institutional spread. European Journal of Clinical Microbiology \& Infectious Diseases, p. 1647-1655, 2015.

ZARKOTOU, O. et al. Risk factors and outcomes associated with acquisition of colistinresistant KPC-producing Klebsiella pneumoniae: A matched case-control study. Journal of Clinical Microbiology, v. 48, n. 6, p. 2271-2274, 2010. 
ZAVASCKI, A. P. et al. Polymyxin B for the treatment of multidrug-resistant pathogens: A critical reviewJournal of Antimicrobial Chemotherapy, 2007.

ZAVASCKI, A. P. Polymyxins for the treatment of extensively-drug-resistant Gram-negative bacteria: from pharmacokinetics to bedside. Expert Review of Anti-infective Therapy, v. 12, n. 5, p. 531-533, 1 maio 2014. 
ANEXO A - Artigo publicado pelo grupo na revista americana Emerging Infectious Diseases.

cause of the illness. The PCR for amplification of a 470-bp fragment of citrate synthase gene was performed according to a previously published protocol (5). DNA was extracted with QIAamp DNA Mini Kit (QIAGEN, Hilden, Germany) from whole blood and the crust of the eschar collected on day 5 of illness. In addition, serum samples were tested by indirect immunofluorescent assay for specific IgG and IgM against Francisella tularensis and Rickettsia spp. (spotted fever and typhus group) 5 days and 10 weeks after onset of fever.

Diagnosis of ATBF was affirmed by positive PCR result from the crust of the eschar; further sequence analysis revealed the infection with $R$. africae. Serologic testing demonstrated seroconversion of $\operatorname{IgG}$ to $R$. conorii and $R$. rickettsii, which cross-reacts with $R$. africae (negative immunofluorescent assay IgG titer at initial testing and 1:1,024 for $R$. conorii and $R$. rickettsii 10 weeks later) (6). Thick and thin blood smears were negative for malaria.

ATBF is the second most well-established cause of febrile illness among travelers to sub-Saharan Africa, after malaria. Usually it manifests by fever $(59 \%-100 \%$ of cases), headache (62\%-83\%), eschar (53\%-100\%), lymphadenopathy $(43 \%-100 \%)$, and rash $(15 \%-46 \%)$. The clini$\mathrm{cal}$ and laboratory findings in the patient reported here were similar to those previously reported among $R$. africae-infected patients (1). In the acute phase of illness, a biopsy and culture from an eschar, as well as PCR, are the most suitable methods to confirm the ATBF diagnosis. In this case, ATBF was proven by PCR and subsequent sequencing from a crust sample but not from whole blood and seroconversion of IgG.

The first information about $R$. africae in ticks in Uganda was published in 2013 by Lorusso et al. (7), but previously $R$. conorii also was found (8). The prevalence rate of R. africae infection among Amblyomma variegatum ticks in Uganda was $97.1 \%(9)$. Recently, Proboste et al. established the presence of previously undetected tickborne pathogens in rural dogs and associated ticks in Uganda. Tick species Haemaphysalis leachi, Rhipicephalus spp., and A. variegatum were infected by Rickettsia spp. (18.9\%), including $R$. conorii and $R$. massiliae; by Ehrlichia spp. (18.9\%), including $E$. chaffeensis; and by Anaplasma platys (10).

Our MEDLINE literature search found no previous descriptions of human $R$. africae infection in Uganda. This case indicates that ATBF should be included as a possible diagnosis in persons with febrile illness who have traveled to Uganda, a well-known tourist destination.

\section{References}

1. Jensenius M, Fournier PE, Kelly P, Myrvang B, Raoult D. African tick bite fever. Lancet Infect Dis. 2003;3:557-64. http://dx.doi.org/10.1016/S1473-3099(03)00739-4

2. Kelly PJ, Beati L, Mason PR, Matthewman LA, Roux V, Raoult D. Rickettsia africae sp. nov., the etiological agent of
African tick bite fever. Int J Syst Bacteriol. 1996;46:611-4. http://dx.doi.org/10.1099/00207713-46-2-611

3. Parola P, Paddock CD, Socolovschi C, Labruna MB, Mediannikov O, Kernif T, et al. Update on tick-borne rickettsioses around the world: a geographic approach. Clin Microbiol Rev. 2013;26:657-702. http://dx.doi.org/10.1128/CMR.00032-13

4. Jensenius M, Fournier PE, Vene S, Hoel T, Hasle G, Henriksen AZ, et al.; Norwegian African Tick Bite Fever Study Group. African tick bite fever in travelers to rural sub-Equatorial Africa. Clin Infect Dis. 2003;36:1411-7. http://dx.doi.org/10.1086/375083

5. Roux V, Rydkina E, Eremeeva M, Raoult D. Citrate synthase gene comparison, a new tool for phylogenetic analysis, and its application for the rickettsiae. Int J Syst Bacteriol. 1997;47:25261. http://dx.doi.org/10.1099/00207713-47-2-252

6. Fournier PE, El Karkouri K, Leroy Q, Robert C, Giumelli B, Renesto P, et al. Analysis of the Rickettsia africae genome reveals that virulence acquisition in Rickettsia species may be explained by genome reduction. BMC Genomics. 2009;10:166 http://dx.doi.org/10.1186/1471-2164-10-166

7. Lorusso V, Gruszka KA, Majekodunmi A, Igweh A, Welburn SC, Picozzi K. Rickettsia africae in Amblyomma variegatum ticks, Uganda and Nigeria. Emerg Infect Dis. 2013;19:1705-7. http://dx.doi.org/10.3201/eid1910.130389

8. Socolovschi C, Matsumoto K, Marie JL, Davoust B, Raoult D, Parola P. Identification of Rickettsiae, Uganda and Djibouti. Emerg Infect Dis. 2007;13:1508-10. http://dx.doi.org/10.3201/ eid1310.070078

9. Nakao R, Qiu Y, Igarashi M, Magona JW, Zhou L, Ito K, et al. High prevalence of spotted fever group rickettsiae in Amblyomma variegatum from Uganda and their identification using sizes of intergenic spacers. Ticks Tick Borne Dis. 2013;4:506-12. http://dx.doi.org/10.1016/.ttbdis.2013.07.001

10. Proboste T, Kalema-Zikusoka G, Altet L, Solano-Gallego L, Fernández de Mera IG, Chirife AD, et al. Infection and exposure to vector-borne pathogens in rural dogs and their ticks, Uganda. Parasit Vectors. 2015;8:306. http://dx.doi.org/10.1186/s13071-015-0919-x

Address for correspondence: Petra Bogovic, Department of Infectious Diseases, University Medical Center Ljubljana, Japljeva 2, 1525

Ljubljana, Slovenia; email: petra.bogovic@kclj.si

\section{Polymyxin B Resistance in Carbapenem-Resistant Klebsiella pneumoniae, São Paulo, Brazil}

Flávia Bartolleti, Bruna Mara Silva Seco, Carla Capuzzo dos Santos, Carolina Bragança Felipe, Mara Elisa Borsato Lemo, Tatiane da Silva Alves, Lilian F. Passadore, Marcelo J. Mimica, Suely Carlos Ferreira Sampaio, Alexandre Prehn Zavascki, Jorge Luiz Mello Sampaio

Author affiliations: University of São Paulo School of Pharmaceutical Sciences, São Paulo, Brazil (F. Bartolleti, 
B.M.S. Seco, J.L. Mello Sampaio); Santa Casa de São Paulo School of Medical Sciences, São Paulo (F. Bartolleti, M.J. Mimica, S.C.F. Sampaio); Fleury Medicine and Health, São Paulo (C.C. dos Santos, C.B. Felipe, M.E.B. Lemo, T.S. Alves, J.L.M. Sampaio); University of São Paulo, São Paulo (L.F. Passadore); Hospital de Clínicas de Porto Alegre, Porto Alegre, Brazil (A.P. Zavascki)

DOI: http://dx.doi.org/10.3201/eid2210.160695

To the Editor: Infections caused by carbapenem-resistant Enterobacteriaceae have been associated with higher death rates than infections caused by carbapenem-susceptible strains, and resistant infections are mostly treated with polymyxins (1). Several outbreaks caused by carbapenemand polymyxin-resistant Klebsiella pneumoniae (CPRKp) have been reported, mainly from Europe, and represent an emerging threat.

Carbapenem-resistant $K$. pneumoniae (CRKp) are endemic to Brazil, where polymyxin B (PMB) has been largely used against infections caused by these microorganisms. We evaluated PMB resistance rates and clonal diversity among CRKp isolates from patients in São Paulo, Brazil. The study was approved by the Research Review Board of Fleury Institute in São Paulo.

All $K$. pneumoniae isolates, except those from urine and active surveillance samples, recovered from inpatients during January 1, 2011-December 31, 2015, at 10 private tertiary-care hospitals in São Paulo were included in the study. K. pneumoniae isolates were identified by matrixassisted laser desorption/ionization time-of-flight mass spectrometry; we analyzed only the first isolate from each patient, unless other isolates were recovered after a 90-day interval. To determine antimicrobial drug MICs, we used nonautomated broth microdilution (2) polystyrene plates with cation-adjusted Mueller-Hinton broth (Becton Dickinson, Franklin Lakes, NJ, USA) for PMB and tigecycline; the Etest (bioMérieux, Marcy l'Etoile, France) for fosfomycin; and the disk-diffusion method (3) for all other antimicrobial drugs. Isolates with a MIC of $\leq 2 \mathrm{mg} / \mathrm{L}$ for PMB were considered susceptible; this value is the EUCAST (European Committee on Antimicrobial Susceptibility Testing) breakpoint for colistin in Enterobacteriaceae (2). Tigecycline and fosfomycin MICs were interpreted according to EUCAST guidelines (2). Imipenem and meropenem MICs were determined using the Etest for all isolates that were nonsusceptible to at least 1 carbapenem (ertapenem, meropenem, or imipenem) by disk-diffusion (3). We phenotypically detected class A carbapenemases as previously described (4).

We used convenience sampling to select 62 CPRKp isolates that were detected during 2014-2015 and used pulsed-field gel electrophoresis (PFGE) to evaluate their genomic DNA macrorestriction profiles after $X b a \mathrm{I}$ digestion. Dice similarity indexes were calculated using the UPGMA method with $1.25 \%$ tolerance and optimization (5). The minimal Dice index for a clonal group was defined as $80 \%$.

We performed multilocus sequence typing as described (http://bigsdb.web.pasteur.fr/klebsiella/klebsiella html) for 11 isolates that represented the 2 major PFGE clonal groups, CPRKp1 and CPRKp2. The full bla ${ }_{\mathrm{KPC}}$ nucleotide sequence was determined for these isolates (online Technical Appendix Table 1, http://wwwnc.cdc.gov/EID/ article/22/11/16-0695-Techapp1.pdf).

We included a total of $3,085 \mathrm{~K}$. pneumoniae isolates in the analysis (online Technical Appendix Table 2). A significant increase in carbapenem resistance $(\mathrm{p}<0.001)$ was seen from $2011(6.8 \%)$ to 2015 (35.5\%) (Figure, panel A). During the last year of analysis, we detected $K$. pneumoniae carbapenemase (KPC) in $96.2 \%$ of CRKp isolates.

PMB MICs showed a bimodal distribution that was clearly differentiated by a $2 \mathrm{mg} / \mathrm{L}$ MIC (Figure, panel B). When we stratified MICs by year and carbapenem resistance, a significantly increasing trend of resistance was seen among CRKp isolates from $2011(0 \%)$ to 2014 $(24.8 \%)$ to $2015(27.1 \%)(\mathrm{p}<0.001)$ (Figure, panel C). Resistance among carbapenem-susceptible $K$. pneumoniae varied from $0.7 \%$ in 2011 to $3.9 \%$ in 2014 ( $\mathrm{p}=0.002$ ).

We did not evaluate the mechanism of PMB resistance. However, this resistance in KPC-producing $K$. pneumoni$a e$ is probably caused by the loss of $\operatorname{mgr} B$ function or the presence of nonsynonymous substitutions in $p m r B$ that upregulate the $p m r C A B$ and $a r n B C A D T E F$-pmrE operons, resulting in modification of lipid A. All these genes are located on the bacterial chromosome. Susceptibility testing showed that amikacin and tigecycline were the most active non- $\beta$-lactam antimicrobial agents against CPRKp isolates (amikacin 73.8\%, tigecycline 69.4\%) and CRKp isolates (amikacin $79.9 \%$, tigecycline $72.2 \%$ ) (online Technical Appendix Table 3).

PFGE identified 2 major clonal groups. The largest group, CPRKp1 $(\mathrm{n}=30)$, belonged to sequence type (ST) 11 , and the other group, CPRKp2 $(\mathrm{n}=17)$, belonged to ST437. Both STs belonged to clonal complex (CC) 258. Interhospital and intrahospital dissemination among private and public hospitals was observed. All isolates tested had the $b l a_{\mathrm{KPC}-2}$ gene (online Technical Appendix Figure).

In a previous study, the PMB resistance rate was $27 \%$ among $22 \mathrm{CRKp}$ isolates from patients at a tertiary hospital in São Paulo during 2008-2010 (6). This rate is much higher than the rate we obtained for 2010 , possibly because the previous study had a small number of isolates. CPRKp has been reported in various European countries at rates similar to those we report (7).

The predominance of CC258 among KPC-2-producing $K$. pneumoniae, but not among CPRKp, was reported 
in Brazil (8), and ST11, a variant of ST258, has occasionally been detected in colistin-resistant KPC-producing isolates in Spain (9). The ST437 clone has been reported in KPC-2 producers in China (10), but we found no reports

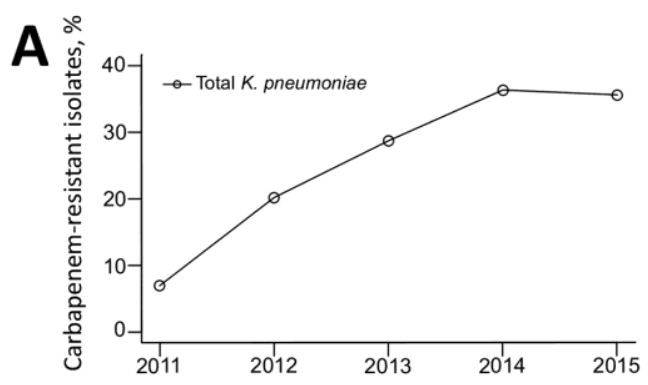

B

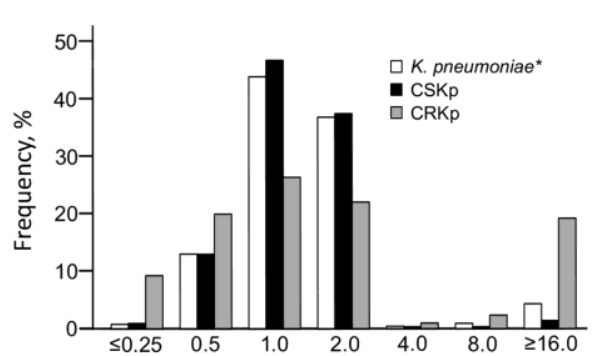

C

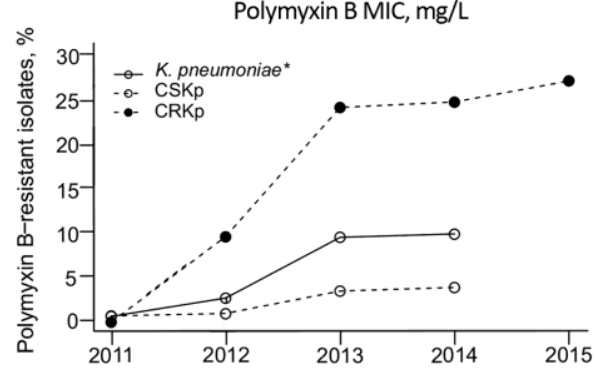

Figure. Antimicrobial resistance profile of Klebsiella pneumoniae isolated from hospital inpatients in São Paulo, Brazil. A) Carbapenem resistance trend among all $K$. pneumoniae isolates cultured during January 1, 2011-December 31, 2015 ( $n=$ $3,085 ; p<0.001)$. B) Polymyxin B MIC distribution stratified by carbapenem susceptibility. C) Polymyxin B resistance trend stratified by carbapenem susceptibility, 2011-2015. B, C Carbapenem-susceptible K. pneumoniae (CSKp) isolated during January 1, 2011-June 30, $2014(n=1,511)$ and carbapenemresistant $K$. pneumoniae (CRKp) isolated during January $1,2011-$ December 31, $2014(n=436) ;{ }^{*}$ during July 1, 2015-December 31 2015 , only CRKp were tested for polymyxin B susceptibility $(n=$ 377). All statistical analyses were conducted using SAS Studio 3.4 (SAS Institute, Inc., Cary, NC, USA). The statistical significance of a trend in resistance rates was evaluated using the $\chi^{2}$ test, in which $p$ values $<0.05$ were considered significant: $K$. pneumoniae, $p<0.001 ;$ CSKp, $p=0.004 ;$ CRKp, $p=0.003$. of CPRKp among this clonal group. Our findings show an alarming yearly increase in the rate of PMB resistance among CRKp isolates, mostly KPC-2 producing, and the occurrence of interhospital and intrahospital dissemination of CPRKp from CC258 in São Paulo.

This work was supported by a grant from the Fleury Institute, São Paulo, Brazil. F. Bartolleti was supported by a scholarship from the National Counsel of Technological and Scientific Development (CNPq).

\section{References}

1. Falagas ME, Tansarli GS, Karageorgopoulos DE, Vardakas KZ. Deaths attributable to carbapenem-resistant Enterobacteriaceae infections. Emerg Infect Dis. 2014;20:1170-5. http://dx.doi.org/10.3201/eid2007.121004

2. European Committee on Antimicrobial Susceptibility Testing. Breakpoint tables for interpretation of MICs and zone diameters, version 5.0 [cited 2016 Aug 12]. http://www.eucast.org/fileadmin/ src/media/PDFs/EUCAST_files/Breakpoint_tables/v_5.0 Breakpoint Table 01.pdf

3. Clinical and Laboratory Standards Institute. Performance standards for antimicrobial susceptibility testing; twenty-fifth informational supplement (M100-S25). Wayne (PA) The Institute; 2015.

4. Tsakris A, Kristo I, Poulou A, Themeli-Digalaki K, Ikonomidis A, Petropoulou D, et al. Evaluation of boronic acid disk tests for differentiating KPC-possessing Klebsiella pneumoniae isolates in the clinical laboratory. J Clin Microbiol. 2009;47:362-7. http://dx.doi.org/10.1128/JCM.01922-08

5. Heras J, Dominguez C, Mata E, Pascual V, Lozano C, Torres C, et al. GelJ—a tool for analyzing DNA fingerprint gel images. BMC Bioinformatics. 2015;16:270. http://dx.doi.org/10.1186 s12859-015-0703-0

6. Pereira GH, Garcia DO, Mostardeiro M, Ogassavara CT, Levin AS Spread of carbapenem-resistant Klebsiella pneumoniae in a tertiary hospital in Sao Paulo, Brazil. J Hosp Infect. 2011;79:182-3. http://dx.doi.org/10.1016/j.jhin.2011.05.023

7. Giske CG. Contemporary resistance trends and mechanisms for the old antibiotics colistin, temocillin, fosfomycin, mecillinam and nitrofurantoin. Clin Microbiol Infect. 2015;21:899-905.

http://dx.doi.org/10.1016/j.cmi.2015.05.022

8. Andrade LN, Curiao T, Ferreira JC, Longo JM, Climaco EC, Martinez R, et al. Dissemination of bla $_{\mathrm{KPC}-2}$ by the spread of Klebsiella pneumoniae clonal complex 258 clones (ST258, ST11, ST437) and plasmids (IncFII, IncN, IncL/M) among Enterobacteriaceae species in Brazil. Antimicrob Agents Chemother. 2011;55:3579-83. http://dx.doi.org/10.1128/ AAC. $01783-10$

9. Ruiz-Garbajosa P, Curiao T, Tato M, Gijon D, Pintado V, Valverde A, et al. Multiclonal dispersal of KPC genes following the emergence of non-ST258 KPC-producing Klebsiella pneumoniae clones in Madrid, Spain. J Antimicrob Chemother. 2013;68:2487clones in Madrid, Spain. J Antimicrob Ch

10. Wang LH, Wei DD, Wan LG, Yu Y, Deng Q, Liu Y. Diversity of the genetic environment of the $b l a_{\mathrm{KPC}-2}$ gene among Klebsiella pneumoniae clinical isolates in a Chinese hospital. Microb Drug Resist. 2016;22:15-21. http://dx.doi.org/10.1089/ mdr.2014.0281

Address for correspondence: Jorge Luiz Mello Sampaio, Faculdade de Ciências Farmacêuticas, Avenida Professor Lineu Prestes, 580, Butantã, São Paulo, SP, Brazil, 05508-900; e-mail: sampaio@usp.br 
ANEXO B - Figura 10 ampliada.

Coeficiente de similaridade de Dice (\%)

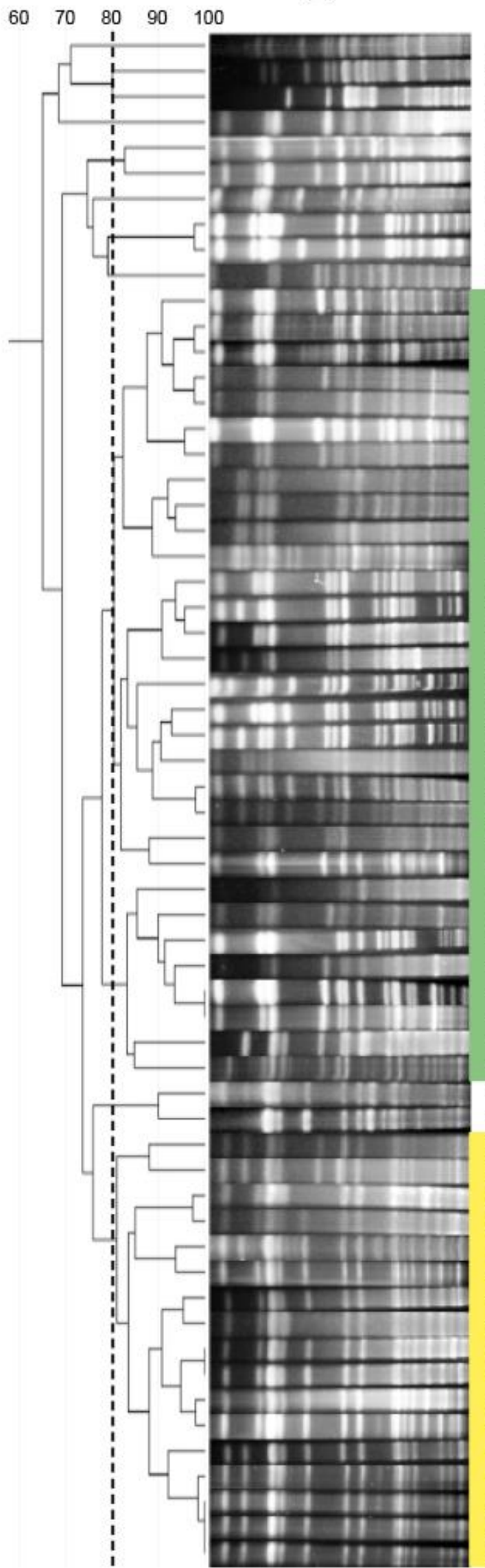

\begin{tabular}{|c|c|c|c|c|c|c|}
\hline ID & DATA & HOSP & CIM PMB & PFGE & MLST & $m g r B$ \\
\hline 1157 & out-14 & A & 16 & & ST16 & $\mathrm{N}$ \\
\hline 3089 & ago-14 & z & 16 & & - & $\mathrm{N}$ \\
\hline 3540 & out-14 & C & $\geq 64$ & & - & $\mathrm{T}$ \\
\hline 8762 & jul-14 & $\mathrm{J}$ & $\geq 64$ & & - & $\mathrm{N}$ \\
\hline 3522 & fev-15 & C & 32 & & - & $\mathrm{T}$ \\
\hline 3587 & jan-15 & C & $\geq 64$ & & - & $\mathrm{T}$ \\
\hline 1108 & ago-14 & A & 32 & & - & $\mathrm{N}$ \\
\hline 8778 & mar-14 & $J$ & 264 & & - & $\mathrm{T}$ \\
\hline 4451 & $\operatorname{mar}-14$ & $\mathrm{H}$ & $\geq 64$ & & - & $\mathrm{T}$ \\
\hline 4067 & ago-14 & $\mathrm{E}$ & $\geq 64$ & & - & $\mathrm{N}$ \\
\hline 1178 & jan-15 & A & 16 & & - & $\mathrm{N}$ \\
\hline 1140 & mai-14 & A & $\geq 64$ & & - & $\mathrm{T}$ \\
\hline 1128 & mar-14 & A & 32 & & - & $\mathrm{N}$ \\
\hline 4499 & $a b r-14$ & $\mathrm{H}$ & 16 & & ST11 & $\mathrm{N}$ \\
\hline 4041 & $a b r-14$ & $\mathrm{E}$ & $\geq 64$ & & - & $\mathrm{N}$ \\
\hline 4462 & mar-14 & $\mathrm{H}$ & 32 & & - & $\mathrm{T}$ \\
\hline 4028 & $a b r-14$ & $E$ & $\geq 64$ & & - & $\mathrm{T}$ \\
\hline 4159 & jun-14 & $\mathrm{F}$ & 32 & & - & $\mathrm{N}$ \\
\hline 4156 & dez-14 & $\mathrm{F}$ & $\geq 64$ & & - & $\mathrm{N}$ \\
\hline 4123 & ago-14 & $\mathrm{F}$ & $\geq 64$ & & ST11 & $\mathrm{N}$ \\
\hline 4483 & fev-15 & $\mathrm{H}$ & 32 & & ST11 & $\mathrm{N}$ \\
\hline 3552 & mar-14 & C & 16 & & - & $T$ \\
\hline 3572 & mar-14 & c & $\geq 64$ & & - & $\mathrm{T}$ \\
\hline 3509 & mai-14 & C & 16 & & ST11 & $\mathrm{T}$ \\
\hline 3518 & jun-14 & C & $\geq 64$ & & - & $T$ \\
\hline 3574 & jan-15 & C & 264 & CPRKp1 & - & $\mathrm{T}$ \\
\hline 3568 & mar-14 & C & 32 & & - & $\mathrm{N}$ \\
\hline 3533 & mar-15 & $\mathrm{C}$ & 16 & & ST11 & $\mathrm{N}$ \\
\hline 3598 & jul-14 & C & $\geq 64$ & & - & $\mathrm{T}$ \\
\hline 4008 & mar-14 & $\mathrm{E}$ & 32 & & - & $T$ \\
\hline 4050 & mai-14 & $E$ & 8 & & - & $T$ \\
\hline 3578 & nov-14 & C & 16 & & - & $\mathrm{T}$ \\
\hline 4444 & fev-15 & $\mathrm{H}$ & 16 & & - & $T$ \\
\hline 1487 & out-14 & D & 264 & & - & $\mathrm{T}$ \\
\hline 1264 & jul-14 & $\mathrm{B}$ & 264 & & - & $\mathrm{N}$ \\
\hline 3528 & fev-15 & C & 16 & & ST11 & $\mathrm{T}$ \\
\hline 4254 & set-14 & G & 32 & & - & $\mathrm{N}$ \\
\hline 4021 & fev-15 & $E$ & 32 & & ST11 & $T$ \\
\hline 4492 & fev-15 & $\mathrm{H}$ & 16 & & - & $T$ \\
\hline 4012 & out-14 & $E$ & $\geq 64$ & & - & $\mathrm{T}$ \\
\hline 4406 & mar-14 & $\mathrm{H}$ & $\geq 64$ & & - & T \\
\hline 1497 & mar-15 & D & $\geq 64$ & & - & $\mathrm{N}$ \\
\hline 1187 & $a b r-14$ & A & 32 & & - & $\mathrm{N}$ \\
\hline 3588 & dez-14 & C & 16 & & ST437 & $\mathrm{N}$ \\
\hline 3551 & ago-14 & $\mathrm{C}$ & 32 & & - & $\mathrm{N}$ \\
\hline 4334 & $a b r-14$ & 1 & $\geq 64$ & & ST437 & $T$ \\
\hline 4455 & $a b r-14$ & $\mathrm{H}$ & 32 & & - & $\mathrm{T}$ \\
\hline 1414 & mar-15 & D & 32 & & - & $\mathrm{T}$ \\
\hline 4425 & jan-15 & $\mathrm{H}$ & 16 & & - & $\mathrm{N}$ \\
\hline 4430 & jun-14 & $\mathrm{H}$ & 264 & & - & $T$ \\
\hline 4340 & jul-14 & 1 & 264 & & - & $\mathrm{N}$ \\
\hline 5018 & out-14 & Z & $\geq 64$ & CPRKp2 & ST437 & $\mathrm{T}$ \\
\hline 8346 & jun-14 & Z & 32 & & - & $T$ \\
\hline 3893 & fev-15 & z & 32 & & - & $\mathrm{N}$ \\
\hline 4473 & fev-14 & $\mathrm{H}$ & $\geq 64$ & & - & $\mathrm{N}$ \\
\hline 4371 & $a b r-14$ & 1 & 16 & & - & $\mathrm{T}$ \\
\hline 4358 & mar-14 & 1 & 264 & & - & $T$ \\
\hline 4354 & $\operatorname{mar}-14$ & 1 & 16 & & ST437 & $\mathrm{T}$ \\
\hline 4313 & jan-15 & 1 & 16 & & - & $T$ \\
\hline 4293 & mar-14 & G & $\geq 64$ & & - & $\mathrm{T}$ \\
\hline
\end{tabular}

